\title{
ESTUDIO MACROFLORÍSTICO DEL AFLORAMIENTO MIOCENO DE CONCRECIONES CARBONÁTICAS DE IZARRA (ÁLAVA, ESPAÑA). ASPECTOS TAFONÓMICOS, PALEOECOLÓGICOS Y BIOESTRATIGRÁFICOS
}

\author{
Eduardo BARRÓN \\ Departamento de Geociências, Universidade de Aveiro, 3180 Aveiro \\ (Portugal).
}

Barrón, E. 1999. Estudio macroflorístico del afloramiento mioceno de concreciones carbonáticas de Izarra (Álava, España). Aspectos tafonómicos, paleoecológicos y bioestratigráficos. [Megafloral study of a Miocene outcrop of calcareous concretions in Izarra (Álava, Spain). Taphonomic, palaeoecological and biostratigraphic aspects]. Revista Española de Paleontología, 14 (1), 123-145. ISSN 0213-6937.

\begin{abstract}
Plant remains are studied from inside and on the surface of calcareous concretions of Miocene age at Izarra (Álava, Spain). The concretions formed under hypersaline lacustrine conditions where microbial mats developed. 31 taxa are identified among remains belonging to the divisions Pteridophyta, Pinophyta and Magnoliophyta. Coniferous trees such as Tetraclinis salicornioides and Pinus sp. and shrubs grew under subtropical dry open forests. In the riparian areas lauraceous forests composed by different species of the families Lauraceae, Sterculiaceae, Myricaceae and Juglandaceae dominated. A subtropical climate is inferred with mesophyllous plants which probably had abscission at the driest season. The Tertiary age of the calcareous concretions from Izarra has been established on the basis of an analysis of the palaeobotanical record.
\end{abstract}

Keywords: Plant megafossils, calcareous concretions, Taphonomy, Palaeoecology, Biostratigraphy, Miocene, Izarra, Álava, Spain.

\section{RESUMEN}

Se realiza un estudio macroflorístico del afloramiento mioceno de Izarra (Álava, España). Los fósiles vegetales se han encontrado sobre o en el interior de concreciones calcáreas formadas en fondos lacustres hipersalinos en donde se desarrollaron velos microbianos. Este estudio ha permitido inferir la presencia de 31 taxones, pertenecientes a las divisiones Pteridophyta, Pinophyta y Magnoliophyta. El análisis de las asociaciones registradas indica que la vegetación que existió en la zona fue un bosque abierto subtropical compuesto por coníferas, como Tetraclinis salicornioides y'Pinus sp., y arbustos. En zonas riparias, se desarrolló una laurisilva dominada por distintas especies de las familias Lauraceae, Sterculiaceae, Myricaceae y Juglandaceae. Se ha inferido la climatología que existió en la zona que fue subtropical, en la cual las especies mesófilas posiblemente sufrieron abscisión en el período más seco. Por otra parte, se realiza a partir del los datos paleobotánicos una revisión de la edad terciaria de las concrecciones calcáreas.

Palabras clave: Macroflora, concreciones calcáreas, Tafonomía, Paleoecología, Bioestratigrafía, Mioceno, Izarra, Álava, España.

\section{INTRODUCCIÓN Y ANTECEDENTES}

El afloramiento mioceno de Izarra (Álava, España) presenta materiales que se depositaron en una cuenca lacustre que se conocía poco desde el punto de vista paleobotánico. Las campañas de recolecta que se han realizado en el afloramiento, han proporcionado una gran cantidad de restos vegetales, fundamentalmente hojas, aunque también se han hallado de forma más escasa tallos, semillas aladas y conos masculinos de gimnospermas, y amentos de angiospermas.

Todos los fósiles vegetales que aparecen en este afloramiento se encuentran asociados a concreciones carbonáticas producidas por la acción de tapices bacterianos en una etapa fosildiagenética temprana. Estas concreciones no sólo presentan restos vegetales, sino 


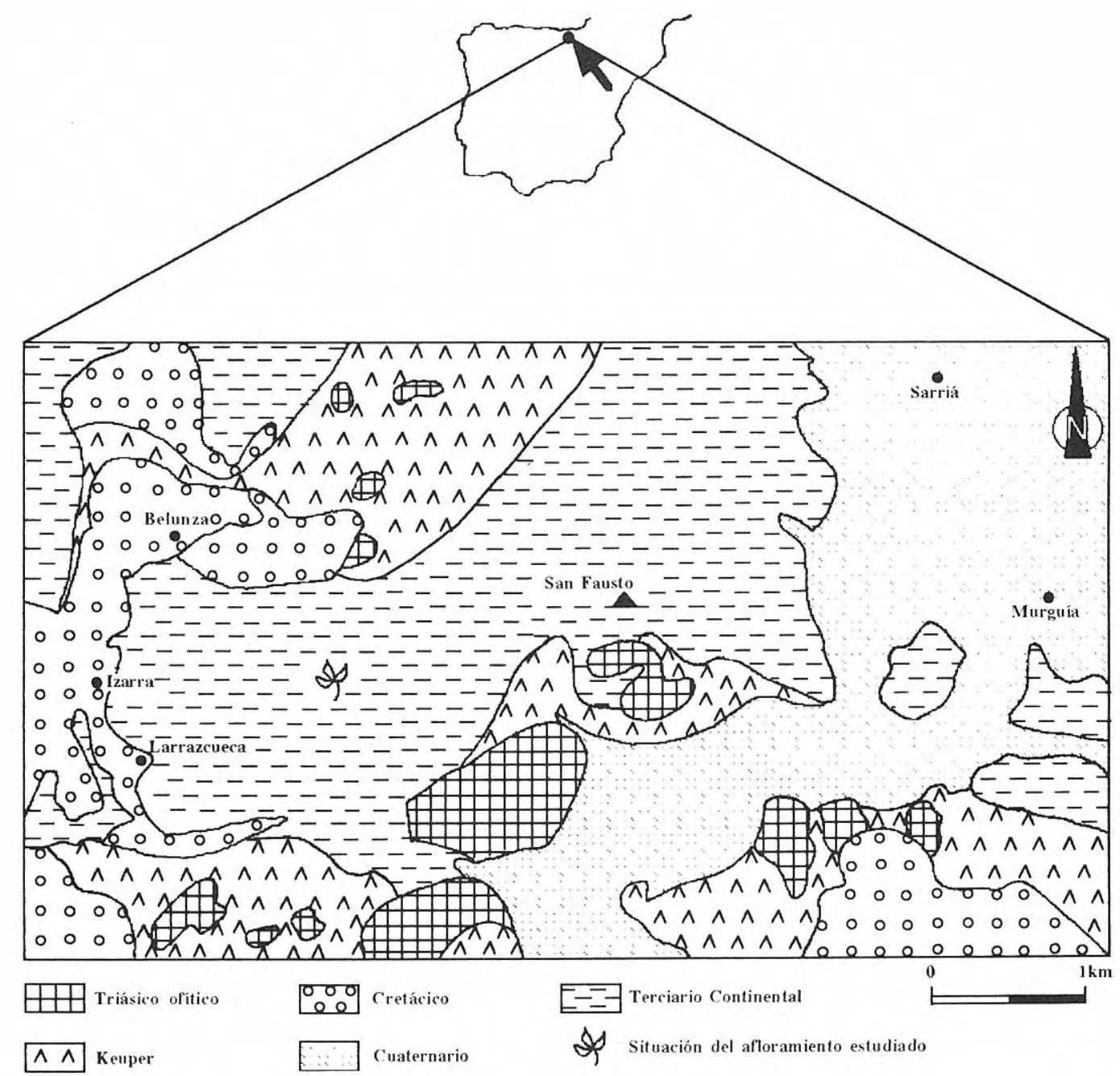

Figura 1. Esquema geológico de la cuenca de Izarra, modificado de Ramírez del Pozo y del Olmo Zamora (1979).

también insectos (Arillo, 1994; Arillo y Ortuño, 1997a, 1997b; Arillo et al., 1996; Nel y Arillo, 1995; Nel et al., 1995, 1997; Ortuño y Arillo, 1997), arácnidos, crustáceos, gasterópodos, peces y plumas de ave.

Izarra es el único afloramiento terciario conocido de la Península Ibérica que muestra fósiles asociados a concreciones carbonáticas, por lo que el estudio de estos, y concretamente, de los macrorrestos vegetales, tiene excepcional interés desde los puntos de vista taxonómico y tafonómico.

Aunque aún existen pocos estudios, en el Mioceno Inferior y Medio la vegetación que se desarrolló en la Península Ibérica fue por lo general de tipo subtropical. En la zona nororiental y en Portugal predominaron taxones xerófitos de tipo paleotropical (Pais, 1979; Suc et al., 1992; Sanz de Siria, 1994); y se formaron estepas en la depresión del Duero (Rivas-Carballo, 1991; RivasCarballo et al., 1994). A lo largo del Mioceno Superior, debido a que la región Mediterránea se aisló del Paratetis, se produjo una evolución ambiental en el sentido de un aumento general y progresivo de las precipitaciones, que produjo una importante expansión de los taxones vegetales de carácter arctoterciario, que gradualmente fueron despla- zando a los paleotropicales; transformándose las zonas esteparias del centro peninsular en estepas arboladas de tipo mediterráneo. El relevo de mayor envergadura parece efectuarse a lo largo del Vallesiense. Por esta razón, aún se hallan taxones paleotropicales indicadores de condiciones de sequía en el Vallesiense inferior, mientras que en su parte media, más de la mitad de los macrorrestos vegetales recolectados en los afloramientos terciarios peninsulares pertenecen a especies arbóreas arctoterciarias de tipo templado (Sanz de Siria, 1994; Barrón et al., 1996).

Las macrofloras miocenas clásicas de la Península Ibérica se localizan, quizás por falta de prospecciones, en el área mediterránea y en Portugal (Barrón et al., 1996). Se deben considerar una excepción las de Épila (Zaragoza), atribuida al Aragoniense medio/superior (Ferrer et al., 1993), y de Frías (Burgos), considerada miocena superior por Álvarez Ramis y Fernández Marrón (1975). Así, el afloramiento de Izarra se halla en una zona de la Península Ibérica en la que casi no existen datos paleobotánicos terciarios, si exceptuamos una cita correspondiente a un corte de la Sección de Guillerna, situada en las cercanías de la localidad de Vitoriano (Álava) (Stackelberg, 1960), en la que se recogió una 
muy pequeña colección de restos foliares y troncos que se asignaron al Mioceno Superior.

El afloramiento de Izarra, como localidad fosilífera, fue estudiado por Fernández Marrón et al. (1979), quienes describen 37 especies, 34 referidas a angiospermas dicotiledóneas, una a gimnospermas y la última a un hongo del género Phacidium que, según los autores, permiten atribuir los materiales del afloramiento al Oligoceno inferior (Estampiense).

Posteriormente, Barrón (1996), coincidiendo en la datación estratigráfica, puso de manifiesto la existencia de dos especies del paragénero Daphnogene a partir de restos foliares polimórficos. Recientemente, Fernández Marrón (1996) realizó un estudio esporopolínico de los materiales del afloramiento. Como resultado citó 33 taxones que relacionó con plantas oligocenas típicas de bosques montanos y climas templados, y vegetación palustre y acuática.

Últimamente, Barrón et al. (1997) hacen una síntesis paleontológica en la cual se critica la edad atribuida a los materiales del afloramiento y se infieren conclusiones de tipo paleoambiental.

\section{CONTEXTO GEOGRÁFICO Y GEOLÓGICO}

El yacimiento de Izarra (Fig. 1) se encuentra localizado unos $4 \mathrm{Km}$ al oeste de Murguía y $2 \mathrm{Km}$ al este de Izarra (Álava, España). Apareció como consecuencia de las obras de desmonte del ramal de la autopista A-68 entre Bilbao y Miranda del Ebro.

Los materiales de este afloramiento se encuentran situados sobre el diapiro de Murguía ubicado en la Cubeta Alavesa del Dominio Cántabro-Navarro (Serrano Oñate et al., 1989). Éste presenta una forma cilíndrica ancha con una elevación de tipo lacolítico (Ramírez del Pozo y Del Olmo Zamora, 1979). En general, las formaciones que lo circundan se encuentran en una cota superior y en casi todo su borde sur el Cretácico y el Keuper aparecen en escamas imbricadas.

El movimiento de este diapiro comenzó en el Albiense con movimientos epirogénicos, continuando en el Cenomaniense y sobre todo en el Turoniense (Stackelberg, 1960). En el Campaniense superior comenzó su ascensión y llegó a aflorar en dicha edad. Movimientos posteriores durante el Eoceno-Oligoceno inclinaron el lacolito. En su zona central quedaron flotando dos bloques del Cretácico Superior (Ramírez del Pozo y Del Olmo Zamora, 1979).

Los sedimentos neógenos de la zona, miocenos según Brinkmann y Lögters (1968), se encuentran rodeados por el diapiro, el cual está intensamente erosionado o denudado por el lavado continuo de sus materiales salinos. Durante el Neógeno, a causa del hundimiento continuo que provocaba el lavado mencionado, en esta zona se formó una cuenca lacustre, en cuyo centro se depositaron arcillas arenosas varvadas, mientras que en sus bordes lo hacían conglomerados (Stackelberg, 1960).

En la zona afloran sedimentos de edad comprendida

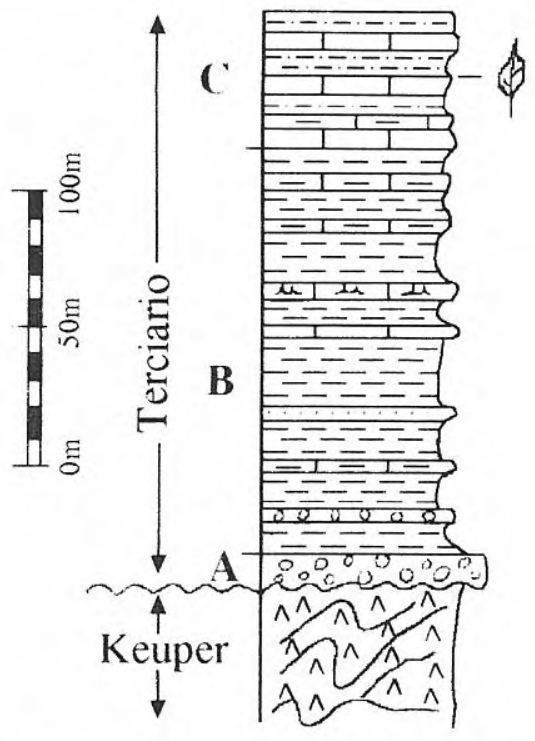

Figura 2. Columa estratigráfica, modificada de Fernández Marrón et al. (1979). A, B y C: tramos de la sucesión estratigráfica.

entre el Albiense y el Maastrichtiense, perforados por materiales salinos del Keuper que constituyen el diapiro de Murguía (Fig. 1). El Terciario continental recubre mediante discordancia angular los términos anteriores y se encuentra suavemente plegado. La sucesión propuesta por Fernández Marrón et al. (1979), es la siguiente (Fig. 2):

a) Conglomerados con cantos calcáreos de hasta 10 $\mathrm{cm}$ de diámetro y cementos también calcáreos de tonos rojizos.

b) Serie detrítica de $150 \mathrm{~m}$ de potencia, formada por arcillas arenosas y margas arcillosas de tonos rojizos, con intercalaciones de conglomerado calizo y algunos bancos de caliza brechoide (en ésta aparecen microfósiles resedimentados del Cretácico Superior).

c) Serie detrítica de unos $50 \mathrm{~m}$, formada por arcillas arenosas y arenas micáceas grises y ocres, con intercalaciones de areniscas y microconglomerados. Existen delgados niveles varvados de calizas arcillosas, alternados con arcillas húmicas también varvadas. Las calizas se presentan en niveles o en forma de concreciones. Éstas son las que contienen las asociaciones fósiles objeto de este estudio.

\section{MATERIAL Y MÉTODOS}

Todos los restos macroscópicos estudiados proceden del tramo $\mathrm{C}$ de la columna estratigráfica, estando siempre ligados a las concreciones calcáreas. La matriz arcillosa y arenosa en la que están englobadas las concreciones no presenta fósiles vegetales. Tampoco se han hallado restos vegetales macroscópicos en las calizas varvadas.

De acuerdo con la nomenclatura propuesta por Fernández López (1981), se encuentran en el afloramiento de Izarra dos tipos de tafones: impresiones, según el 


\begin{tabular}{|c|c|c|c|c|}
\hline TAXONES & $\begin{array}{l}\text { EJEMPLARES } \\
\text { ESTUDIADOS }\end{array}$ & PORCENTAJES & FISONOMÍA & $\begin{array}{c}\text { REQUERIMIENTOS } \\
\text { TÉRMICOS }\end{array}$ \\
\hline \multicolumn{5}{|l|}{ Pteridophyta } \\
\hline $\begin{array}{l}\text { Salvinia sp. } \\
\text { Osmunda parschlugiana } \\
\text { Filicales indet. }\end{array}$ & $\begin{array}{l}6 \\
1 \\
2\end{array}$ & $\begin{array}{c}0,547 \\
0,091 \\
0,18\end{array}$ & $\begin{array}{c}\text { micro/liso } \\
- \\
-\end{array}$ & $\begin{array}{c}\text { Pluri } \\
\text { Pluri } \\
-\end{array}$ \\
\hline \multicolumn{5}{|l|}{ Pinophyta } \\
\hline $\begin{array}{l}\text { Tetraclinis salicornioides } \\
\text { Pinus } \mathrm{sp} \text {. } \\
\text { Gimnosperma indet. (Taxodiaceae?) }\end{array}$ & $\begin{array}{l}25 \\
4 \\
1\end{array}$ & $\begin{array}{l}2,28 \\
0,365 \\
0,091\end{array}$ & $\begin{array}{l}\text { lepto } \\
\text { nano } \\
\text { nano }\end{array}$ & $\begin{array}{l}\text { Meso } \\
\text { Pluri } \\
-\end{array}$ \\
\hline \multicolumn{5}{|l|}{ Magnoliophyta } \\
\hline $\begin{array}{l}\text { Daphnogene polymorpha } \\
\text { Laurophyllum sp. } 1 \\
\text { Laurophyllum sp. } 2 \\
\text { Laurophyllum? sp. } \\
\text { Nymphaeaceae gen. et sp. indet. } \\
\text { Juglans? acuminata } \\
\text { Myrica longifolia } \\
\text { Quercus cf. buchii } \\
\text { Byttneriophyllum tiliaefolium } \\
\text { Sterculiaceae gen. et sp. indet. } \\
\text { Populus balsamoides } \\
\text { Diospyros? Brachysepala } \\
\text { Caesalpiniaceae gen. et sp. indet. } 1 \\
\text { Caesalpiniaceae gen. et sp. indet. } 2 \\
\text { Celastrophyllum sp. } \\
\text { Berchemia multinervis } \\
\text { Sapindus } \text { sp. } \\
\text { Acer } \text { sp. } \\
\text { Acerates cf. veterana } \\
\text { Lomatites sp. } \\
\text { Dicotiledóneas indet. } \\
\text { Amento }\end{array}$ & $\begin{array}{c}170 \\
3 \\
10 \\
13 \\
1 \\
30 \\
31 \\
2 \\
56 \\
1 \\
10 \\
24 \\
8 \\
17 \\
2 \\
15 \\
6 \\
1 \\
46 \\
4 \\
3 \\
1\end{array}$ & $\begin{array}{c}15,51 \\
0,27 \\
0,91 \\
1,186 \\
0,091 \\
2,73 \\
2,83 \\
0,18 \\
5,11 \\
0,091 \\
0,91 \\
2,19 \\
0,729 \\
1,55 \\
0,18 \\
1,37 \\
0,547 \\
0,091 \\
4,2 \\
0,365 \\
0,27 \\
0,091\end{array}$ & $\begin{array}{c}\text { noto/liso } \\
\text { noto/liso } \\
\text { noto/liso } \\
\text { noto/liso } \\
\text { mega/liso } \\
\text { noto/liso } \\
\text { micro/aserrado } \\
\text { noto/aserrado } \\
\text { meso/liso } \\
\text { micro/aserrado } \\
\text { meso/aserrado } \\
\text { noto/liso } \\
\text { micro/liso } \\
\text { micro/liso } \\
\text { micro/aserrado } \\
\text { noto/liso } \\
\text { noto/liso } \\
\text { meso/? } \\
\text { micro/liso } \\
\text { micro/liso } \\
\text { - } \\
\text { - }\end{array}$ & $\begin{array}{c}\text { Meso } \\
\text { Meso } \\
\text { Meso } \\
\text { Meso } \\
\text { Pluri } \\
\text { Meso } \\
\text { Meso } \\
\text { Meso } \\
\text { Mega/meso } \\
\text { Mega/meso } \\
\text { Meso/micro y micro } \\
\text { Meso } \\
\text { Mega/meso } \\
\text { Mega/meso } \\
\text { Mega/meso } \\
\text { Meso } \\
\text { Mega/meso } \\
\text { Meso y Meso/micro } \\
\text { Mega/meso } \\
\text { Mega/meso } \\
-\end{array}$ \\
\hline Amento & & Liliatae & & \\
\hline $\begin{array}{l}\text { Smilax sp. } \\
\text { Commelinidae (restos foliares) } \\
\text { Commelinidae (rizoma) }\end{array}$ & $\begin{array}{c}2 \\
13 \\
1\end{array}$ & $\begin{array}{l}0,18 \\
1,186 \\
0,091\end{array}$ & $\begin{array}{c}\text { micro/? } \\
\text { ?/liso } \\
-\end{array}$ & $\begin{array}{l}\text { Meso } \\
\text { Pluri } \\
\text { Pluri }\end{array}$ \\
\hline Caules & 18 & 1,64 & & \\
\hline Indeterminados & 539 & 49,99 & & \\
\hline TOTAL DETERMINADOS & 1096 & 100 & & \\
\hline
\end{tabular}

Figura 3. Datos macroflorísticos del afloramiento de Izarra. Datos fisonómicos: Lepto: leptófilos, Nano: nanófilos, Micro: micrófilos, Noto: notófilos, Meso: mesófilos, Mega: megáfilos, Liso: margen foliar liso, Aserrado: margen foliar aserrado. Requerimientos térmicos: Mega/meso: mega-mesotérmico, Meso: mesotérmico, Meso/micro: mesomicrotérmico, Micro: microtérmico, Pluri: plurirregional.

concepto de Schopf (1975), en un porcentaje de más de un $90 \%$, y compresiones sin cutícula conservada, en el sentido de Barrón (1993), con alrededor de un $10 \%$ de presencia. Estos tafones, por lo general, aparecen en la superficie de las concreciones, lo que es un factor negativo con respecto a la idónea conservación de los fósiles, ya que un elevado número de éstos han sufrido erosiones que han destruido parte del fósil. Por esta razón, y porque en muchas ocasiones al formarse la concreción no queda englobado totalmente el resto vegetal, en muy raras ocasiones se conservan hojas enteras, llegando hasta nosotros fragmentos centrales de limbos en donde no se pueden observar ni el pecíolo, ni su forma, ni su margen, aunque sí se puede estudiar parcialmente la nerviación foliar. Por consiguiente, casi la mitad de los restos foliares analizados se han considerado indeterminables (Fig. 3).

En total se han estudiado 1.096 ejemplares (Fig. 3) correspondientes en su mayor parte a restos foliares. Para la descripción de éstos se han seguido las nomenclaturas de morfología foliar propuestas por Hickey (1973) y Takhtajan (1991), esta última únicamente hace referencia a la venación foliar. 


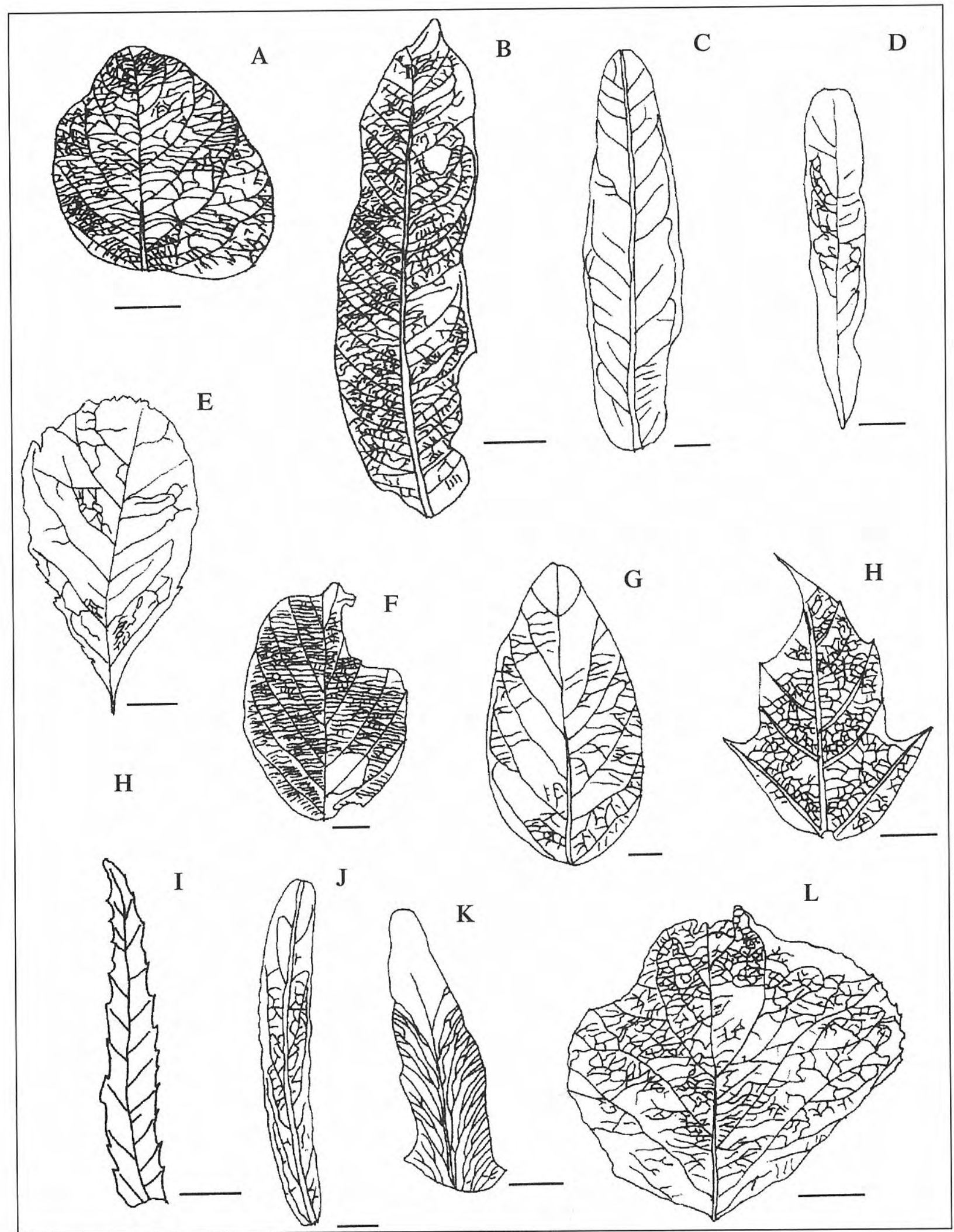

Figura 4. A: Byttneriophyllum tiliaefolium (A. Braun) Knobloch und Kvaček, FM-090. B: Laurophyllum? sp., JLBV-038. C: Laurophyllum sp. 2, FM-115. D: Acerates cf. veterana Heer, FM-207. E: Celastrophyllum sp., MCNA-5590. F: Berchemia multinervis (A. Braun) Heer, JS-6451. G: Diospyros? brachysepala A. Braun, CMA-114. H: Sterculiaceae gen. et sp. indet., FM-252. I: Myrica longifolia Unger, FM-186. J: Lomatites sp., JLBV-016. K: Osmunda parschlugiana (Unger) Andreánszky, JLBV-019. L: Populus balsamoides Goeppert, JLBV-037 (MCNA: Museo de Ciencias Naturales de Álava, FM: colección Félix Murguía, CMA: colección Moreno/Aranguren, JS: colección Javier Sáenz, JLBV: colección José Luis Bueso). Escalas gráficas: A-B, I= 10 mm; C-H, J-L=5mm. 


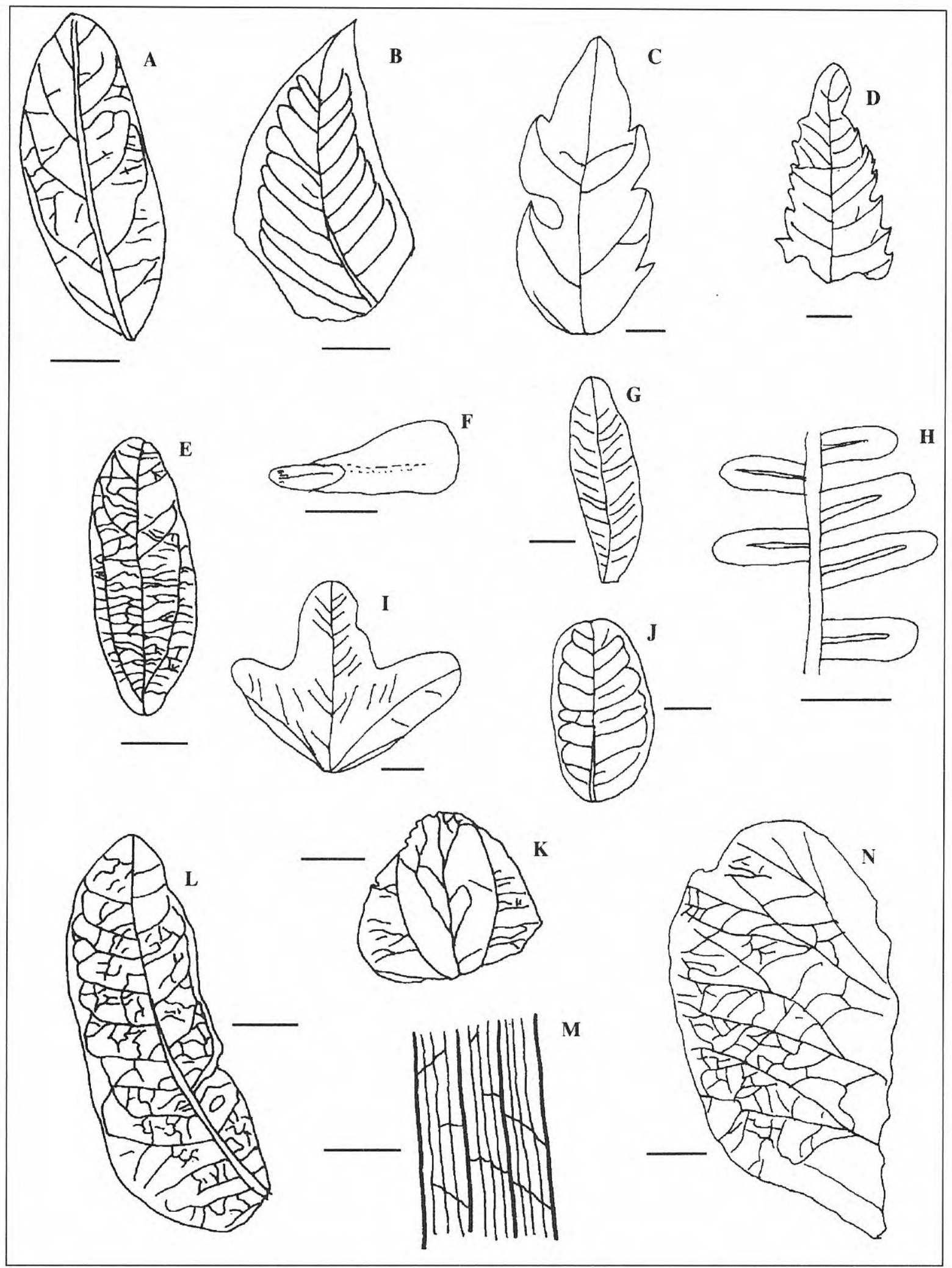

Figura 5. A: Laurophyllum sp. 1, FM-091. B: Sapindus sp., MCNA-3776. C: Quercus cf. buchii Weber, MNCNV-1478. D: Dicotiledónea indet., CMA-104. E: Daphnogene polymorpha (A. Braun) Ettingshausen, FM-192. F: Pinus sp., JLBV-182. G: Caesalpiniaceae gen. et sp. indet. Tipo 1, CMA-062. H: Filicales, CMA-073. I: Acer sp., CMA-030. J: Caesalpiniaceae gen. et sp. indet. Tipo 2, MCNA-3778. K: Smilax sp., FM-230. L: Juglans? acuminata A. Braun ex Unger, FM-104. M: Commelinidae, detalle del ejemplar FM-138. N: Nymphaeaceae gen. et sp. indet., FM-082 (MCNA: Museo de Ciencias Naturales de Álava, MNCNV: Museo Nacional de Ciencias Naturales (CSIC), FM: colección Félix Murguía, CMA: colección Moreno/Aranguren, JLBV: colección José Luis Bueso). Escalas gráficas: A-B, E, H, K= $10 \mathrm{~mm}$; C-D, F-G, I-J, L, N= $5 \mathrm{~mm}$; M= $1 \mathrm{~mm}$. 
Los fósiles estudiados se encuentran depositados en su mayor parte en el Museo de Ciencias Naturales de Álava, integrándose en su propia colección (MCNA), o en la de los señores: José Luis Bueso (JLBV), Javier Sáenz (JS), Félix Murguía (FM) y José María Moreno/Carmela Aranguren (CMA). También se ha estudiado una colección perteneciente al Museo Nacional de Ciencias Naturales (CSIC) (MNCNV), así como ejemplares recogidos por nosotros en diferentes campañas de campo.

Se ha utilizado la nomenclatura propuesta por Fernández López (1991) al considerar los taxones determinados desde un punto de vista paleobiológico y tafonómico.

Para realizar una interpretación paleoclimática se los ha dividido según los requerimientos térmicos de especies actuales próximas a ellos filogenéticamente en el sentido de Van Steenis (1962) y Bessedik (1985). El clima ha sido deducido a partir de las características fisonómicas de los especímenes estudiados, considerándose el tamaño foliar y el tipo de margen según lo expuesto por Bailey y Sinnot (1915, 1916), Raunkiaer (1934) y Webb (1959).

\section{SISTEMÁTICA}

\section{ORDEN SALVINIALES Zimmermann, 1959 \\ Familia Salviniaceae Bartling, 1830 \\ Género Salvinia Micheli, 1729}

\section{Salvinia sp. Lám. I, fig. 3}

Hojas orbiculares, pecioladas; longitud del pecíolo: 0,06$0,14 \mathrm{~cm}$; longitud del limbo: 1,07-1,5 cm; anchura: 0,86$1,68 \mathrm{~cm}$; ápice redondeado; base cuneada; margen liso; nerviación no visible debido a la impresión dejada por los tricomas septados del envés que forman una especie de reticulación con aspecto de malla que ocupa toda la hoja; se adivina una zona central que recorre las hojas desde la base hasta el ápice, sin que se observe un nervio medio.

Se han descrito varias especies de Salvinia fósiles (Heer, 1855-1859; Hantke, 1954; Mai y Walther, 1978; Buzek et al., 1996), pero todas ellas basan al menos su diagnosis en los caracteres de nerviación foliar. Los 6 ejemplares estudiados por nosotros, conservados como compresiones sin trazas cuticulares, no pueden compararse a ninguna de las especies fósiles descritas porque no conservan la nerviación foliar.

Tras revisar pliegos de herbario en el Real Jardín Botánico de Madrid (CSIC), hemos podido observar que entre las especies actuales del género Salvinia, $S$. auriculata Aubl., de Sudamérica, posee ejemplares con tricomas septados muy desarrollados, de forma similar a los restos foliares estudiados en este trabajo. No obstante, tampoco los podemos relacionar con esta especie ya que presenta un patrón de nerviación foliar muy característico imposible de distinguir en los especímenes estudiados.

\section{Osmunda parschlugiana (Unger) Andreánszky, 1959}

Fig. 4, K

*1847 Pteris parschlugiana Unger, 22, lám. 36, fig. 6.

1864 Osmunda strozzii Gaudin y Strozzi, 9, lám. 1, figs. 14.

1959 Osmunda parschlugiana (Unger); Andreánszky, 47, text.-fig. 2, lám. 7, fig. 4.

Pinnula lanceolada; longitud: $3,4 \mathrm{~cm}$; anchura en la zona más basal: $0,83 \mathrm{~cm}$; ápice agudo; base no conservada; margen liso, quizás algo ondulado; nerviación pinnada; gran número de nervios secundarios que salen del nervio medio formando un ángulo de divergencia menor de $45^{\circ}$, sufriendo casi todos dicotomizaciones y terminando en el margen; algunos de los nervios secundarios nacen de un mismo punto; la nerviación no se conserva en la parte apical del ejemplar.

Se ha estudiado un único ejemplar no muy bien conservado (JLBV-019) en forma de impresión. El primer autor que describió pinnulas idénticas a la descrita fue Unger (1847), a partir de ejemplares del Mioceno Superior de Parschlug (Austria), quien las describió de forma errónea como Pteris parschlugiana. Mucho más adelante, Andreánsky (1959) relacionó correctamente estos restos con el género Osmunda, debiendose atribuir a éste la nueva combinación $O$. parschlugiana.

O. parschlugiana se describió a partir de impresiones con morfologías idénticas a las de $O$. regalis L., especie de la que quizás fuera antepasada. Su distribución estratigráfica es típicamente neógena, extendiéndose desde el Burdigaliense hasta el Plaisanciense.

ORDEN CONIFERALES Coulter y Chamberlain, 1910

Familia Cupressaceae Stefanoff, 1940-1941

Género Tetraclinis Masters, 1893

\section{Tetraclinis salicornioides (Unger) Kvaček, 1989 Lám II, figs. 3, 7-8}

*1840 Hellia salicornioides Unger, 375.

1855-1859 Libocedrus salicornioides (Unger); Heer, vol. I, 47, lám. 21, fig. 2.

1989 Tetraclinis salicornioides (Unger); Kvaček, 48, lám. 1, fig. 11, lám. 2, figs. 2-14, lám. 3, figs. 3-4.

Fragmentos de ramas de 0,5-0,15 mm de anchura; polimórficas, con hojas escuamiformes y empizarradas; longitud conservada muy variable: $1-2,24 \mathrm{~cm}$; hojas reunidas en verticilos de 3 en 3 (es posible que existiera una cuarta que no se observa en los ejemplares recolectados) envolviendo dos de ellas, que se destacan al sobresalir por los lados del tallo, a la tercera que se desarrolla debajo de éstas; hojas decurrentes acuminadas y con nervio medio; conos masculinos instalados en los laterales y en los ápices de algunos ejemplares (Lám. II, fig. 8), con un tamaño aproximado de $3 \times 2 \mathrm{~cm}$; presentan unas 3-4 filas de escamas dispuestas de forma helicoidal; ápice de las escamas cuneado. 
Esta especie, de la que se han estudiado unos 25 ejemplares, se presenta en el Mioceno de Izarra con dos tipos fundamentales de morfologías. Una de ellas recuerda las formas descritas como Libocedrites salicornioides (Unger) Endlicher (Pamalarev et al., 1991) y $T$. salicornioides (Petrescu et al., 1995), en el Oligoceno y Mioceno de Europa oriental (Lám. II, fig. 7). Se trata de ejemplares con ramas anchas y planas que recuerdan morfológicamente al actual género Libocedrus. El segundo tipo está constituido por ramas delgadas, cilíndricas, con una anchura muy pequeña, como las del Egeriense de Hungria, descritas como T. salicornioides (Hably, 1993), que recuerdan las del género Tetraclinis (Lám. II, fig. 3). Tanto un tipo como el otro fueron estudiados por Friis (1977) desde un punto de vista anatómico, concluyendo que se trataba de la misma especie, la cual presentaba bastantes similitudes con la actual Tetraclinis articulata (Vahl) Masters, aunque este parecido no era exacto, ya que la especie fósil presentaba aspectos morfológicos y epidérmicos que no coincidían con los de la especie actual. Por esta razón, la autora citada consideró que la especie Hellia salicornioides presentaba valided taxonómica. Recientemente, Kvaček (1989) encontró ramas como las descritas, en conexión orgánica con conos femeninos sin duda asignables al género Tetraclinis. Por esta razón, $H$. salicornioides fue considerada por el autor citado sinónima de $T$. salicornioides. Esta especie aparece en Europa a partir del Eoceno medio, extendiéndose hasta el Plioceno Superior (Pamalarev et al., 1991).

Familia Pinaceae Hutchinson, 1924 Género Pinus Linné, 1753

\section{Pinus sp.}

Fig. 5, F

Piñones alados y adnados; longitud total: 1,4-1,53 cm; semilla elíptica u ovalada, envuelta, al menos en un tercio de su longitud, en el ala, encontrándose algunos ejemplares, como el FM-250, con la parte más redondeada de la semilla en contacto con el ala, siendo ahusada en la zona opuesta; longitud de la semilla: $0,5 \mathrm{~cm}$; anchura de la semilla: $0,2-0,3$ $\mathrm{cm}$; ala con forma trapezoidal o flabeliforme, presentando en su extremo una anchura de 0,45-0,6 cm; longitud del ala: 1$1,03 \mathrm{~cm}$; posiblemente se encontraba recorrida por estrías longitudinales, pero estas no se encuentran bien conservadas.

Se han estudiado cuatro ejemplares atribuibles de forma inequívoca al género Pinus, pero imposibles de relacionar con ninguna especie ni fósil ni actual debido a su mal estado de conservación.
ORDEN LAURALES Lindley, 1833

Familia Lauraceae A. L. de Jussieu, 1789

Género Daphnogene Unger, 1850

\section{Daphnogene polymorpha (A. Braun) \\ Ettingshausen, 1851 \\ Fig. 5, E; Lám. II, fig. 5}

*1845 Ceanothus polymorphus A. Braun, 171.

1851 Daphnogene polymorpha (Unger); Ettingshausen, 16, lám. 2, figs. 23-25.

1979 Cinnamomum lanceolatum (Unger) Heer; Fernández Marrón et al., 9-10, lám. 1, fig. 8.

1996 Daphnogene cinnamomifolia (Brongniart in Cuvier) Unger; Barrón, 47-48.

1996 Daphnogene lanceolata Unger; Barrón, 48-50.

1997 Daphnogene polymorpha (A. Braun) Ettingshausen forma bilinica Sitár y Kvaček, 270, lám. 3, figs. 3-8.

Restos foliares polimórficos, por lo general elípticos (Fig. 5, E) o lanceolados (Lám. II, fig. 5); longitud conservada: 2,5-6,64 cm; anchura: 1,44-2,4 cm; ápice agudo, posiblemente atenuado en algunos ejemplares; base aguda; margen liso; nerviación curvipalmada; los nervios primarios laterales nacen del nervio central de forma alterna u opuesta; en algunos ejemplares 4-6 pares de nervios secundarios curvipinnados, alternos, con ángulo de divergencia de unos $45^{\circ}$; en algunas ocasiones los nervios secundarios se ramifican en su zona más distal y forman arcos en la cercanía del margen foliar; presencia de nervios intersecundarios; en varios ejemplares no se observa esta nerviación secundaria; nerviación terciaria percurrente con curso perpendicular al nervio medio central (Fig. 5, E); nerviación cuaternaria reticulada ortogonalmente, forma areolas poligonales.

Resulta difícil, debido a la anisofilia que presenta este género, determinar los restos foliares hallados a nivel específico (Givulescu, 1996; Givulescu et al., 1996). Aunque algunos autores como Hably (1989) describen hasta 5 especies de Daphnogene en el Oligoceno de Hungría a partir de restos sin cutícula conservada, parece probado que las especies D. cinnamomifolia (Brongt. in Cuvier) Ung. y D. lanceolata Ung. son típicamente oligocenas y oligo-miocenas, mientras que $D$. polymorpha y D. bilinica (Ung.) Kvaček y Knobloch son de edad miocena (Kvaček y Walther, 1974).

Los ejemplares estudiados por nosotros (unos 170) presentan por lo general las características morfológicas típicas de la especie $D$. bilinica, la cual es considerada por Sitár y Kvaček (1997) una forma polimorfa de $D$. polymorpha. Debido a la anterior datación del

\section{Lámina I}

1 Juglans? acuminata A Braun ex Unger, CMA-105 (x1,6).

2 Populus balsamoides Goeppert, FM-262 (x2).

3 Salvinia sp., FM-301 (x1,5).

4 Smilax sp., FM-230 (x1,5).

5 Byttneriophyllum tiliaefolium (A. Braun) Knobloch und Kvacek, FM-099 (x2).
6 Laurophyllum sp. 1, MCNA-3777 (x2).

7 Berchemia multinervis (A. Braun) Heer, JS-6451 (x2,7).

8 Commelinidae (rizoma), CMA-087 (x2,5).

(MCNA: Museo de Ciencias Naturales de Álava, FM: colección Félix Murguía, CMA: colección Moreno/Aranguren, JS: colección Javier Sáenz). 
Lámina I
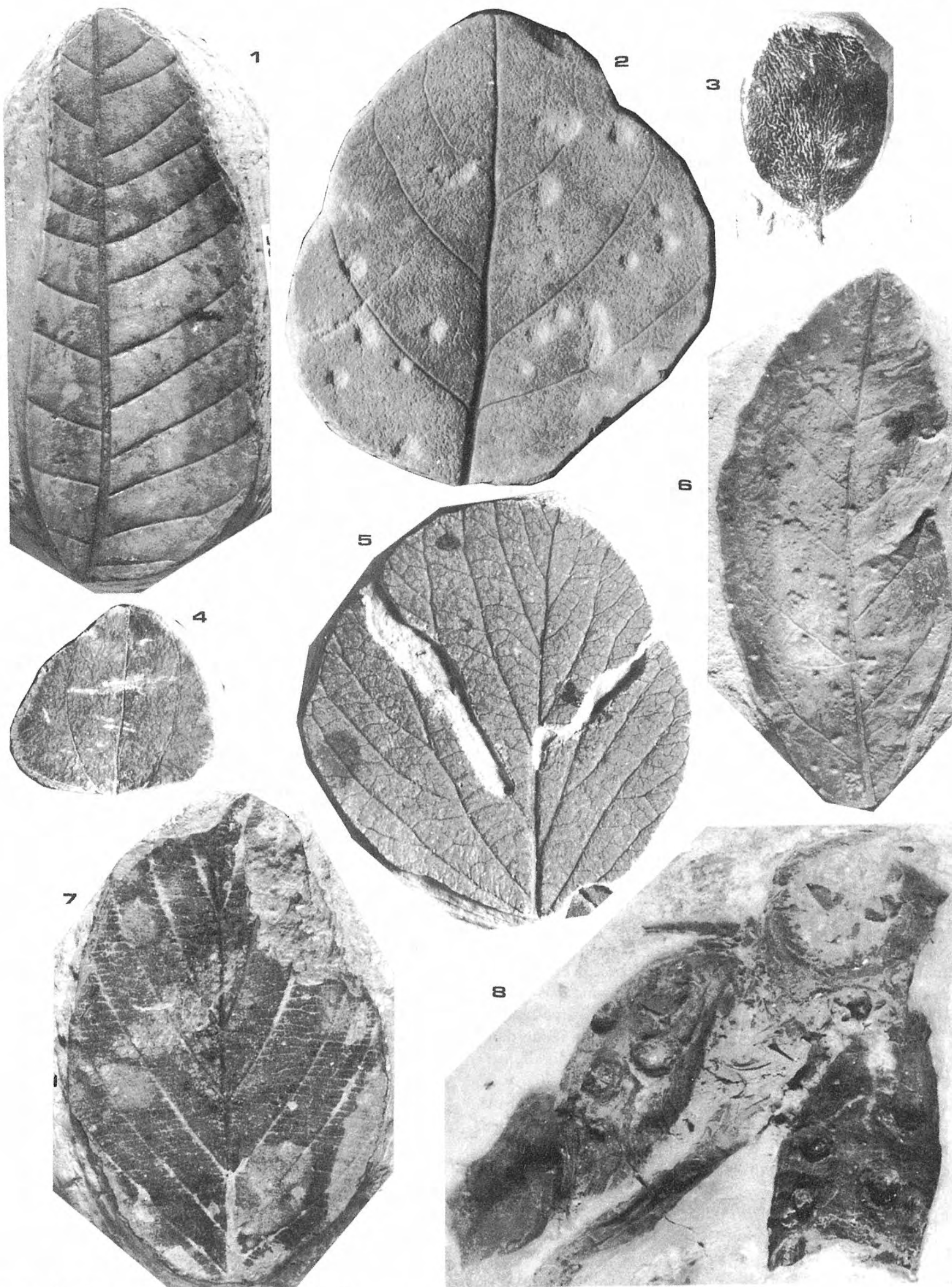

Revista Española de Paleontología, 14 (1), 1999. 
afloramiento estudiado, que se discutirá más adelante, Barrón (1996) relacionó de forma errónea los restos estudiados con las especies $D$. cinnamomifolia y $D$. lanceolata.

E1 descubrimiento en el Neógeno de Krezau (Alemania), en donde se han hallado abundantes restos de Daphnogene, de frutos del tipo de Cinnamomum camphora Nees y Eberm. (Pingen et al., 1994), parece relacionar el género fósil con el actual de Lauraceae.

\section{Género Laurophyllum Goeppert, 1857}

\section{Laurophyllum sp. 1}

Fig. 5, A; Lám. I, fig. 6

Restos foliares elípticos por lo general incompletos; longitud del limbo: 4,3-7,1 cm; anchura: 1,8-2,4 cm; ápice agudo; base de aguda a obtusa; margen liso; nerviación curvipinnada simple; nervio medio moderado con curso recto; 6-9 pares de nervios secundarios de grosor moderado, curvados, por lo general, uniformemente (algunos lo hacen de forma abrupta) con ángulo de divergencia de unos $45^{\circ}$ que no parece variar a lo largo del limbo; presencia de nervios intersecundarios; nerviación terciaria percurrente con curso fundamentalmente derecho, oblicua con respecto al nervio medio.

Se han estudiado 3 ejemplares semejantes a los figurados por Sitár y Kvaček (1997) como "Laurus" primigenia Unger sensu Weyland. Sin embargo, debido a la conservación de estos, por no presentar cutícula, no se pueden atribuir con seguridad al género Laurus, según lo expresado por Ferguson (1974).

Laurophyllum sp. 2

Fig. 4, C; Lám. II, fig. 1

Restos foliares elípticos y estrechos, mal conservados; longitud del limbo: 6,3-6,74 cm; anchura: 1,54-2,05 cm; ápice de agudo a redondeado; base redondeada; margen liso; nerviación curvipinnada lazada simple; nervio medio moderado con curso recto; 6-9 pares de nervios intersecundarios de grosor moderado, abruptamente curvados con ángulo de divergencia de unos $45^{\circ}$; presencia de nervios intersecundarios, usualmente aparecen en número de dos pares en las áreas intercostales de la zona más ancha del limbo; nerviación terciaria, mal conservada, percurrente.

Se han estudiado en total 10 ejemplares que recuerdan a la especie Persea balearica Arènes, del Burdigaliense de la isla de Mallorca (Arènes y Depape, 1956), y a Laurophyllum sp. III, descrito por Hably (1990) en el Egeriense de Hungria. Sin embargo, la falta de cutículas impide relacionar esta especie con el género Persea, ni con ningún otro de la familia Lauraceae.

\section{Laurophyllum? sp.} Fig. 4, B

Restos foliares lanceolados; longitud de limbo: 4,3-8,2 $\mathrm{cm}$; anchura: 1,2-2,1 cm; ápice agudo; base de redondeada a cuneada; margen liso; nerviación curvipinnada simple; nervio primario de moderado a robusto con curso recto; $14-$ 21 pares de nervios secundarios de grosor moderado, curvados uniformemente con ángulo de divergencia agudo, mayor de $45^{\circ}$; presencia de nervios intersecundarios, que en algunas áreas intercostales aparecen en número de dos; nerviación terciaria percurrente con curso, por lo general, derecho, oblicua con respecto al nervio medio; nerviación de rango inferior reticulada ortogonalmente, forma areolas poligonales.

Se han estudiado un total de 13 ejemplares de hojas notófilas lauroides con un elevado número de nervios secundarios, aspecto éste no exclusivo de la familia Lauraceae, por lo que los asignamos con duda al género Laurophyllum. Hemos encontrado un cierto parecido de estos especímenes con los que figura Saporta (1865, 1867) como Quercus elaena Ung. y Andromeda, procedentes del Oligoceno de Saint-Jean-de-Garguier y Mioceno Inferior del Bois d'Assom, respectivamente, y los que describe Hably (1994) como $Q$. elaena y $Q$. apocynophyllum Ett., en el Egeriense de Hungría. Sin embargo, no podemos asignarlos a los géneros Quercus y Andromeda debido a que no presentan dos pares de nervios intersecundarios por cada área intercostal. Sería necesario realizar estudios cuticulares para poder atribuir los ejemplares a algún género en concreto.

\section{ORDEN NYMPHAEALES J. H. Schoffner, 1929 Familia Nymphaeaceae Salisbury, 1805}

Nymphaeaceae gen. et sp. indet. Fig. 5, N

Resto foliar muy deteriorado por lo que no es observable su forma; longitud conservada: $5,2 \mathrm{~cm}$; anchura: $2,7 \mathrm{~cm}$; margen no conservado; nerviación posiblemente rectipalmada; nervios de primer orden ramificados en la cercanía del margen, a veces esta ramificación parece casi una dicotomía; los nervios de segundo orden conectan de forma percurrente los primarios, algunas veces de forma bastante irregular, formando una malla intrincada; no se observa nerviación terciaria.

Se ha estudiado un único ejemplar de pequeño tamaño (FM-082), asignable a la familia Nymphaeaceae. Sanz de Siria (1992), atribuye restos semejantes a la especie Nymphaea ameliana Saporta, del Aquitaniense de Francia. El espécimen estudiado por nosotros bien se podría asemejar a esta especie, como a cualquier otra de la familia Nymphaeaceae, por eso no se determina a nivel genérico ni específico.

ORDEN JUGLANDALES Engler, 1892

Familia Juglandaceae A. Richard ex Kunth, 1824 Género Juglans Linné, 1753

\section{Juglans? acuminata A. Braun ex Unger 1850} Fig. 5, L; Lám. I, fig. 1

\footnotetext{
*1845 Juglans (Carya?) acuminata A. Braun, 170. 1850b Juglans acuminata Unger, 468.
} 
Fragmentos de folíolos, por lo general asimétricos, elípticos y lanceolados; longitud del limbo: 4,66-6,7 cm; anchura: 2,4-2,6 cm; ápice agudo; base generalmente cuneada; margen liso; nerviación curvipinnada lazada; nervio de primer orden moderado con curso ligeramente curvado; 8-10 pares de nervios secundarios de grosor moderado, curvados abruptamente con ángulo de divergencia agudo, mayor de $45^{\circ}$; en algunos ejemplares existencia de arcos inframarginales; presencia de nervios intersecundarios; nerviación terciaria percurrente con curso recto y ahorquillado, oblicua o paralela con respecto al nervio medio; no se observa nerviación de rango inferior.

El estudio de 30 ejemplares ha permitido su atribución sin dudas a esta especie típica del Oligoceno y Neógeno, la cual se asigna con duda a Juglans debido a que la arquitectura y anatomía foliar de los géneros Carya, Cyclocarya, Juglans y Pterocarya en algunos casos es idéntica (Manchester, 1987).

ORDEN MYRICALES Engler, 1892

Familia Myricaceae Blume, 1829

Género Myrica Linné, 1753

\section{Myrica longifolia Unger, 1850 \\ Fig. 4, I; Lám. II, fig. 4} *1850a Myrica longifolia Unger, 29, lám. 6, fig. 2 .
1863 Myricophyllum zachariense Saporta, 66, lám. 8, fig.
2.

Restos foliares lanceolados; longitud del limbo: 4,4-5,3 cm; anchura: 0,8-1,2 cm; ápice agudo; base de redondeada à cuneada; margen aserrado; dientes de pequeño tamaño, espaciados de forma regular o irregularmente dispuestos, cóncavo-rectos y con ángulo apical agudo; nerviación rectipinnada compuesta; nervio medio de moderado a robusto con curso recto; gran cantidad de nervios de segundo orden (en algunos ejemplares, como el CJLBV-196, se cuentan hasta 34 pares, posiblemente debido a que los nervios intersecundarios, que están presentes, tienen un grosor idéntico al de los nervios secundarios), los que terminan en los dientes son uniformemente curvados, mientras que los que se unen con un nervio secundario o intersecundario se desarrollan de forma abrupta; nervios secundarios, por lo general, con ángulo de divergencia de unos $45^{\circ}$, pudiendo poseer una mayor medida, hasta $90^{\circ}$, en algunos ejemplares, como el FM-117; nerviación terciaria reticulada al azar que forma areolas poligonales.

Autores clásicos como Heer (1855-1859) asignaron erróneamente restos foliares como los estudiados al género Dryandroides que pertenece a la familia Proteaceae, típica del Hemisferio Sur. Por su parte, Saporta (1863) dudó en asignar este tipo de especímenes a las familias Proteaceae y Myricaceae, por lo que creó el género Myricophyllum. Estudios posteriores, tanto morfológicos como cuticulares, relacionaron hojas del tipo de las descritas con la familia Myricaceae, como ya expresó Unger (1850b) a partir de estudios morfológicos.

La especie estudiada tiene una distribución estratigráfica oligocena y miocena, y como le ocurre a las actuales, posee polimorfismo foliar. Así, algunos de los ejemplares estudiados en el Aquitaniense del valle de Jiului (Rumanía) (Givulescu y Olos, 1973), relacionados con las especies $M$. banksiaefolia Unger y $M$. lignitum (Unger) Saporta, deberían asignarse a $M$. longifolia debido a la estrechez de sus limbos y a la gran cantidad de nervios secundarios que poseen. La especie actual que más recuerda a $M$. longifolia es $M$. aethiopica L., del África tropical.

ORDEN FAGALES Engler, 1892

Familia Fagaceae Dumortier, 1829 Género Quercus Linné, 1753

\section{Quercus cf. buchii Weber, 1851}

Fig. 5, C

Hojas incompletas, posiblemente elípticas; longitud del limbo: $3,5 \mathrm{~cm}$; anchura: $1,7 \mathrm{~cm}$; ápice muy desarrollado, agudo; base redondeada; margen aserrado; dientes marginales muy desarrollados con ángulo apical agudo; nerviación rectipinnada compuesta; nervio medio moderado con curso recto; 3-4 pares de nervios secundarios de grosor moderado, uniforme o abruptamente curvados, con ángulo de divergencia de unos $45^{\circ}$; posible existencia de nervios intersecundarios observada en el ejemplar MNCNV-1478 (Fig. 5,C); nerviación terciaria no conservada.

Aunque la presencia de $Q$. buchii en el Sarmatiense suizo fue ratificada por Hantke (1965), los ejemplares tipo descritos y figurados por Weber (1851, lám. 19, fig. 4) en el Mioceno de la Baja Renania, podrían no ser asignables al género Quercus, tratándose de hojas polimórficas de Pungiphyllum cruciatum (A. Braun) Frankenhäuser y Wilde, dicotiledónea fósil fundamentalmente miocena, de afinidades botánicas hasta ahora desconocidas (Sitár y Kvaček, 1997).

Los ejemplares estudiados recuerdan a los del Sarmatiense de la Molasa y Oehningen figurados por Heer (1855-1859, lám. 77, figs.13-15) como Q. buchii. Sin embargo, también presentan ciertas semejanzas con otras especies de quercíneas descritas en Oehningen por el autor anterior, como son: $Q$. cuspiformis Heer, del que nuestros ejemplares se diferencian porque posee forma lanceolada y margen ondulado, y $Q$. furcinervis Ung., que a diferencia de los especímenes de Izarra presenta espinas y nerviación secundaria de curso recto.

Debido a la semejanza que los ejemplares estudiados poseen con las dos especies mencionadas y al mal estado de conservación de estos, los asignamos con duda a la especie $Q$. buchii.

ORDEN MALVALES Lindley, 1833

Familia Sterculiaceae Bartling, 1830

Género Byttneriophyllum Knobloch y Kvacek, 1965

$$
\begin{gathered}
\text { Byttneriophyllum tiliaefolium (A. Braun) } \\
\text { Knobloch y Kvaček, } 1965 \\
\text { Fig. 4, A; Lám. I, figs. } 5
\end{gathered}
$$

*1845 Cordia tiliaefolia A. Braun, 170. 
1965a Byttneriophyllum tiliaefolium (A. Braun); Knobloch y Kvaček, 123-166, text.-fig. 1-8, láms. 1-5, lám. 6, figs. 1-3.

1965b Byttneriophyllum tiliaefolium (A. Braun); Knobloch y Kvaček, 201-208, láms. 1-2.

Hojas asimétricas, con forma casi circular u ovada; longitud: 3,9-6,16 cm; anchura: 3,5-4 cm; ápices y bases redondeados; margen liso; nerviación curvipinnada simple; nervio primario robusto con curso recto; 6-10 pares de nervios secundarios uniformemente curvados de grosor moderado, con ángulos de divergencia de unos $45^{\circ}$ (en algunos ejemplares varía, siendo de menor medida en el ápice y de mayor en la zona basal); en algunos casos los nervios secundarios se ramifican en su zona más apical, formando arcos inframarginales; ocasionalmente dos nervios secundarios nacen en un mismo punto del nervio medio (ejemplar FM-281); se observan escasos nervios intersecundarios; nerviación terciaria percurrente de curso simple o ahorquillado, recto o algo convexo; los nervios terciarios forman con el medio ángulos rectos; nerviación de $4^{\circ}$ y $5^{\circ}$ orden reticulada ortogonalmente, forma areolas poligonales. Únicamente se ha encontrado un resto foliar peciolado, correspondiente a un ejemplar juvenil (CJBLV003), el pecíolo es recto y presenta unos $2,5 \mathrm{~cm}$ de longitud.

Se han estudiado 56 ejemplares, por lo que esta especie, típicamente miocena, es la segunda más abundante en el afloramiento de Izarra, posiblemente esto sea debido a que se encontraba ligada a zonas pantanosas (Hably, 1992), bien como nanofanerófito, bien como liana.

Fernández Marrón et al. (1979) hicieron referencia a B. tiliaefolia, pero erróneamente indicaron que no difiere prácticamente en nada de las formas cretácicas del género Credneria, asignándole un alcance estratigráfico muy amplio que en la práctica no posee.

Estudios morfológicos y anatómicos parecen relacionar la especie que nos ocupa con la familia Sterculiaceae en sentido amplio y no en concreto con el género Byttneria, al cual se parece morfológicamente (Knobloch y Kvaček, 1965a, 1965b; Knobloch, 1969).

\section{Sterculiaceae gen. et sp. indet.} Fig. 4, H

Ejemplar ovado; longitud: $2,36 \mathrm{~cm}$; anchura máxima: $1,74 \mathrm{~cm}$; distancia desde la zona de máxima anchura a la base: $0,84 \mathrm{~cm}$; ápice agudo, es posible que se encontrara algo atenuado; base redondeada; margen aserrado; dientes marginales con mucho desarrollo, decreciendo de tamaño según se asciende hacia el ápice desde la zona basal; ángulo apical agudo; serración cóncavo-convexa; nerviación rectipinnada simple; nervio medio robusto con curso recto; se observan cinco pares de nervios secundarios de grosor moderado, curvados uniformemente y con ángulo de divergencia de unos $45^{\circ}$; presencia de nervios intersecundarios que en las partes más basales presentan un grosor semejante al de los nervios de segundo orden; nerviación terciaria desarrollada al azar, reticulada ortogonalmente, que forma areolas poligonales; algunas de las areolas se encuentran ramificadas.

Se ha estudiado un único ejemplar (FM-252) que posee una morfología muy parecida a la que presentan las hojas actuales de algunas especies australianas del género Brachychyton, como B. discolor F. Muell. El estudio de un solo espécimen, nos hace ser precavidos en la asignación de éste a un género actual australiano de posible origen gondwánico, por eso se determina a nivel familiar. El género Brachychyton reune árboles subtropicales adaptados a ambiente xéricos.

ORDEN SALICALES Lindley, 1833

Familia Salicaceae Mirbel, 1815

Género Populus Linné, 1753

\section{Populus balsamoides Goeppert, 1855}

Fig. 4, L; Lám. I, fig. 2

*1855 Populus balsamoides Goeppert, 23, lám. 16, fig. 2.

1855-1859 Populus melanaria Heer, vol. II, 16, lám. 54, fig. 7a, lám. 57, fig. 1.

1979 Populus gaudini Fisher; Fernández Marrón et al., 8, lám. 1, fig. 1 .

Restos foliares muy fragmentarios, en los que no se conserva ni la forma, ni el ápice, ni la base, ni el margen (Lám. I, fig. 5), aunque se han encontrado algunos ejemplares completos, orbiculados y suborbiculados, de pequeño tamaño (Fig. 4, L); longitudes conservadas: 3-7,5 $\mathrm{cm}$; anchuras: 3,2-6 cm; ápice de agudo a acuminado; base redondeada; margen aserrado; dientes marginales, en mayor número que nervios secundarios, cóncavo-convexos y con ángulo apical agudo; nerviación curvipinnada semilazada; nervio medio de grosor de moderado a fino con curso recto o curvado; 4-5 pares de nervios secundarios de grosor moderado con curso recto, uniforme o abruptamente curvado (esto último ocurre en la zona apical del ejemplar CJLBV-

\section{Lámina II}

1 Laurophyllum sp. 2, FM-236 (x3).

2 Lomatites sp., FM-314 (x5).

3 Tetraclinis salicornioides (Unger) Kvaček, FM-222 (x6,6).

4 Myrica longifolia Unger, FM-308 (x2,5).

5 Daphnogene polymorpha (A. Braun) Ettingshausen, JS$334(\times 2,5)$.

6 Acerates cf. veterana Heer, FM-035 (x2).
7 Tetraclinis salicornioides (Unger) Kvaček, FM-076 (x1,75).

8 Tetraclinis salicornioides (Unger) Kvaček, CMA-007 (x6,6).

9 Diospyros? brachysepala A. Braun, CMA-114 (x2).

10 Amento, FM-041 (x3,3).

(FM: colección Félix Murguía, CMA: colección Moreno/Arangurẹn, JS: colección Javier Sáenz). 

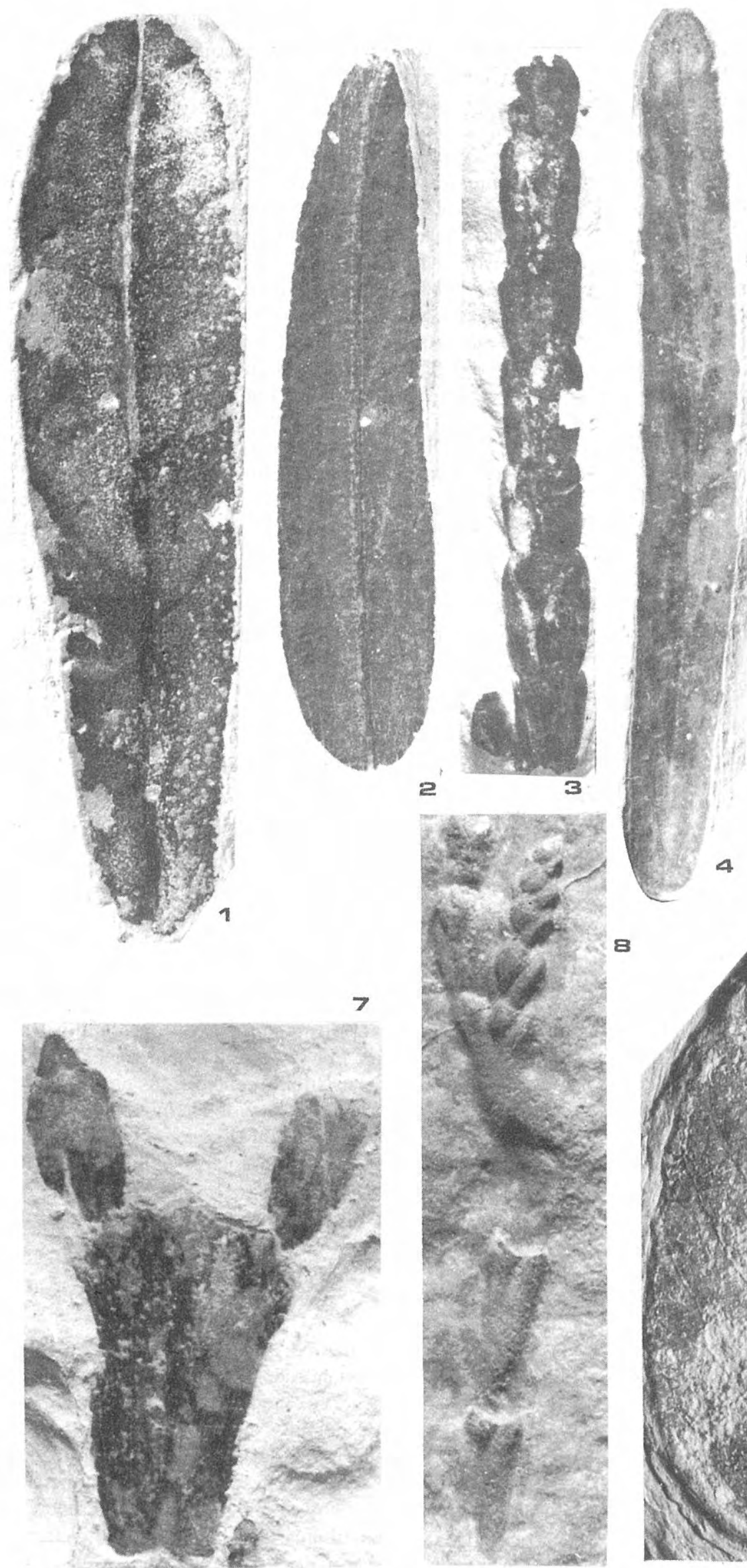

.

Lámina II
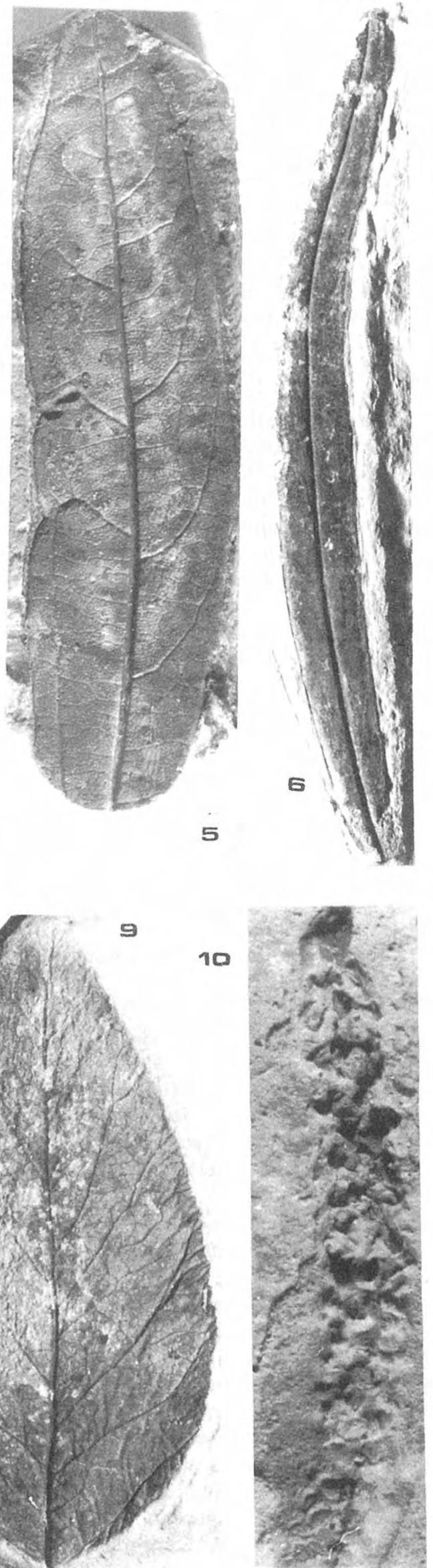
037, Fig. 4, L) y ángulo de divergencia de unos $45-85^{\circ}$, no variando en todo el limbo de los ejemplares orbiculados o suborbiculados; presencia de ramificaciones al final de algunos nervios secundarios que van a terminar en los dientes marginales; presencia de nervios intersecundarios, en ejemplares de tamaño grande, hasta dos por cada área intercostal; nerviación terciaria percurrente con curso derecho y ahorquillado, oblicua con respecto al nervio medio; nerviación de rango inferior reticulada ortogonalmente, forma areolas poligonales.

Se ha estudiado un número de 10 ejemplares que por lo general se encuentran en estado fragmentario (Lám. I, fig. 2), salvo algunos ejemplares orbiculados y suborbiculados, quizás porque la forma de estos se adapta mejor a las estructuras redondeadas de las concreciones en donde se hallan (Fig. 4, L). En particular, estos especímenes orbiculados y suborbiculados recuerdan a los descritos por Heer (1855-1859) como P. melanaria, los cuales no son sino una forma polimórfica de $P$. balsamoides (Hantke, 1954).

$P$. balsamoides parece encontrarse relacionado con las especies norteamericanas actuales $P$. balsamifera L. y $P$. trichocarpa T. y G. (Becker, 1972, 1973). Su distribución estratigráfica va desde el Oligoceno terminal hasta el Plioceno, encontrándose sus restos en Europa y Norteamérica.

ORDEN EBENALES Engler, 1892

Familia Ebenaceae Gürke in Engler y Prantl, 1891 Género Diospyros Linné, 1753

\section{Diospyros? brachysepala A. Braun, 1836} Fig. 4, G; Lám. II, fig. 9

*1836 Diospyros brachysepala A. Braun, 513. 1855-1859 Diospyros anceps Heer, vol. III, 3, 5, 12, lám. 102, figs. $15-18$.

Limbos foliares de elípticos a ovados; longitud: 2,76-4,42 cm; anchura: 1,6-3,18 cm; ápice agudo; base redondeada; margen liso; nerviación curvipinnada simple; nervio medio de robusto a moderado, con curso recto; 5-7 pares de nervios secundarios de grosor moderado, curvados uniformemente con ángulo de divergencia agudo moderado; en algunos ejemplares, como el MCNA-5642, se observa que los nervios secundarios apicales presentan un ángulo de divergencia agudo, mayor de $45^{\circ}$; presencia de nervios intersecundarios, en algunas ocasiones en número de dos por área intercostal, siendo uno de ellos más corto que el otro (esto le ocurre al ejemplar MCNA-1422); nerviación terciaria percurrente con curso recto y ahorquillado; nervios terciarios oblicuos con respecto al nervio medio; nerviación de rango inferior reticulada ortogonalmente que forma areolas poligonales.

La diagnosis de esta especie, de la cual hemos estudiado 24 ejemplares, fue realizada a partir de restos foliares y flores. La aparición de estos dos tipos de fósiles es conocida en el Oligoceno de Hungría (Hably, 1985) y en el Sarmatiense de Oehningen (Heer, 1855-1859). Nosotros únicamente hemos encontrado restos foliares que poseen morfologías que pueden llegar a confundirse con especies de familias muy diferentes. Por ejemplo, Hably y Kvaček (1997) señalaron que un estudio cuticular de algunos ejemplares del Plioceno Inferior de Hungría, morfológicamente idénticos a $D$. brachysepala, relacionó estos con Trigonobalanopsis rhamnoides (Rossm.) Kvacek y Walther, de la familia Fagaceae.

Por nuestra parte, hemos estudiado especímenes, como el MCNA-1422, con características morfológicas semejantes a algunos ejemplares del Egeriense de Hungría determinados por Hably (1988) como cf. Castanopsis toscana (Bandulska) Kräusel y Weyland. Por esta razón, y a la espera de que aparezca algún resto floral o palinomorfo que nos confirme sin duda la presencia del género Diospyros en la zona, consideramos la especie $D$. brachysepala con duda.

ORDEN FABALES Bromhead, 1838

Familia Caesalpiniaceae R. Brown in Flinders, 1814

Caesalpiniaceae gen. et sp. indet.

Tipo 1 (Fig. 5, G):

Folíolos estrechos y ovados; longitud: $2-2,7 \mathrm{~cm}$; anchura: 0,55-1 cm; no se observa el ápice; base cuneada; margen liso; nerviación curvipinnada simple; nervio primario moderado con curso recto; hasta 10 pares de nervios secundarios moderados, curvados uniformemente con ángulo de divergencia agudo, mayor de $45^{\circ}$; presencia de nervios intersecundarios que algunas veces se ramifican; no se observa nerviación terciaria ni de rango inferior.

Tras el estudio de 7 ejemplares, observamos que, en conjunto, podrían pertencer a la especie Cassia phaseolites Unger, ya que presentan un gran parecido con el ejemplar figurado por Heer (1855-1859, lám. 137, fig. 68). No obstante, los especímenes CJLBV-148 y CMA026 también podrían compararse con la especie Leguminosites Sactimartini Heer, porque presentan una nerviación densa y nervios secundarios con ángulos de divergencia casi rectos. Por su parte, el ejemplar FM-283, aunque posee las características mencionadas en los otros dos ejemplares, presenta una mayor anchura del limbo, por lo que podría relacionarse con el género Podogonium.

Debido al bajo número de ejemplares estudiado y a su polimorfismo creemos más correcto reunirlos a nivel familiar como Caesalpiniaceae que asignarlos a un género determinado.

\section{Tipo 2 (Fig. 5, J):}

Folíolos elípticos; longitud: 2,2-3,18 cm; anchura: 1,1$1,55 \mathrm{~cm}$; ápice y base redondeados; margen liso; nerviación curvipinnada simple; nervio medio moderado con curso derecho; 7-8 pares de nervios secundarios moderados, curvados abruptamente cerca del margen con ángulo de divergencia casi recto; presencia de nervios intersecundarios; en algunos ejemplares, como el CJLBV051, presencia de arcos intramarginales; nerviación terciaria mal conservada, posiblemente percurrente; no se observa nerviación de menor rango. 
Tras analizar 17 ejemplares y después de compararlos con distintas especies fósiles de leguminosas descritas, respectivamente, por Heer (1855-1859) y por Zastawniak (1980), en sedimentos sarmatienses de Suiza y Polonia, concluimos que podrían atribuirse por sus características morfológicas tanto al género Caesalpinia como al género Cassia, razón por la cual se mencionan en este trabajo únicamente a nivel familiar.

ORDEN CELASTRALES Wettstein, 1907

Familia Celastraceae R. Brown in Flinders, 1914 Género Celastrophyllum Goeppert, 1852

\section{Celastrophyllum sp. Fig. 4, E}

Restos foliares deteriorados, usualmente no conservan gran parte del margen ni el ápice; forma ovada; pecíolo recto con $2 \mathrm{~mm}$ de longitud; longitud del limbo: 1,6-2,8 cm; anchura: 0,9-1,6 cm; ápice no conservado; base cuneada; margen aserrado; dientes marginales mal conservados, pequeños, con el ángulo apical agudo; nerviación curvipinnada semilazada; nervio medio moderado de curso recto; 5-6 pares de nervios secundarios de grosor moderado, de curso recto o uniformemente curvado, con ángulo de divergencia de unos $45^{\circ}$, midiendo menos en las zonas basales; presencia de nervios intersecundarios; nerviación terciaria reticulada al azar; no se observa nerviación de rango inferior.

El estudio de dos únicos ejemplares nos revela un cierto parecido de estos con Celastrus cassinefolius Unger, del Sarmatiense de Oehningen (Heer, 1855-1859). Sin embargo, no podemos atribuir los especímenes estudiados a esta especie ya que, como hemos indicado, no tienen bien conservados ni el margen ni la zona apical. También pudieran ser comparados con C. splendidus Sap. del Oligoceno la cuenca de Marsella (Saporta, 1865), aunque hay ciertos aspectos en la nerviación de esta especie que no se observan, posiblemente a causa del estado de conservación de los ejemplares estudiados.

Teniendo en cuenta su morfología y nerviación podríamos comparar los ejemplares de Izarra con Celastrophyllum sp. 1, del Burdigaliense-Helvetiense de Znojmo, Moravia (Knobloch, 1969). Sin embargo, a diferencia de los especímenes estudiados, esta especie posee el margen lobulado en su región apical.

Debido a su morfología y a falta de estudios cuticulares que adscriban sin duda los restos estudiados al género Celastrus, creemos oportuno incluir los ejemplares estudiados en el paragénero Celastrophyllum, sin relacionarlo con ninguna especie en particular, a la espera de que aparezcan nuevos ejemplares.

ORDEN RHAMNALES Lindley, 1833

Familia Rhamnaceae A.L. de Jussieu, 1789 Género Berchemia Necker, 1790

\section{Berchemia multinervis (A. Braun) Heer, 1855-} 1859

Fig. 4, F; Lám I, fig. 7
*1836 Rhamnus multinervis A. Braun, 513.

1855-1859 Berchemia multinervis (A. Braun); Heer, vol. III, 77-78, lám. 123, figs. 9-18.

Hojas elípticas; longitud: 3,67-4 cm; anchura: 1,77-1,8 $\mathrm{cm}$; ápices agudos y obtusos; bases obtusas y redondeadas; margen liso; nerviación curvipinnada simple; nervio medio moderado de curso recto; 9-11 pares de nervios secundarios de grosor moderado, uniformemente curvados con ángulo de divergencia de unos $45^{\circ}$; en algunos casos dos nervios secundarios nacen en el mismo punto del nervio medio (ejemplar MCNA-5646); no se observan nervios intersecundarios; nerviación terciaria muy densa, percurrente; nervios terciarios con curso simple, rectos y perpendiculares con respecto al nervio medio; nerviación cuaternaria reticulada ortogonalmente, forma areolas poligonales.

De esta especie miocena se han estudiado 15 ejemplares. En la literatura paleobotánica se han descrito algunas especies de Rhamnaceae con características similares a las de B. multinervis, como por ejemplo Rhamnus sp. 1, del Oligoceno superior de Hungría (Andreánszky, 1966), que posee una nerviación semejante a la de los especímenes estudiados, presentando a diferencia de estos el margen aserrado. En el Egeriense del NO de Hungría, Hably (1990), describe la especie de afinidad botánica desconocida Phyllites skofleki la cual presenta la disposición de la nerviación terciaria semejante a la de nuestros ejemplares, aunque ésta es menos densa y sus nervios secundarios no se desarrollan de forma tan regular como la de los de $B$. multinervis.

Según Hantke (1954), esta especie es similar a $B$. voluvilis DC. que vive actualmente en los estados del S de Norteamérica. También hemos encontrado semejanzas con B. lineata (L.) DC. y B. polyphylla Wall ex Lows. de Asia oriental.

\section{ORDEN SAPINDALES Bentham y Hooker, 1862 \\ Familia Sapindaceae A. L. de Jussieu, 1789 Género Sapindus Linné, 1753}

\section{Sapindus sp.}

Fig. 5, B

Restos foliares incompletos, posiblemente elípticos o lanceolados; longitud conservada de los limbos: 1,6-5,7 cm; anchura conservada: $0,69-1,54 \mathrm{~cm}$; ápice agudo; no se conserva la base; margen liso; nerviación curvipinnada simple o lazada simple; nervio medio moderado con curso recto; más de 13 pares de nervios secundarios moderados curvados uniforme y abruptamente, con ángulo de divergencia agudo, mayor de $45^{\circ}$; presencia de nervios intersecundarios; no se observa nerviación terciaria ni de rango inferior.

Debido a la morfología conservada de los 6 restos estudiados, así como al desarrollo de la nerviación que estos poseen, deben ser atribuidos al género Sapindus. Sin embargo, al encontrarse incompletos, no hemos podido asignarlos a ninguna especie en particular, al igual 
que los ejemplares, también descritos como Sapindus sp., del Egeriense del NO de Hungria (Hably, 1988).

\author{
Familia Aceraceae A.L. de Jussieu, 1789 \\ Género Acer, 1753
}

\section{Acer sp.}

Fig. 5, I

Se ha estudiado un único fragmento foliar (CMA-030), muy deteriorado, con forma tripalmada, que no conserva ni los márgenes, ni los ápices, ni la base. Posiblemente perteneció a una hoja pentalobulada, ya que se conservan cuatro nervios basales de primer orden. Longitud del fragmento del limbo: 2,6 cm, anchura máxima conservada: 2,9 $\mathrm{cm}$, distancia de la zona de máxima anchura a la base: $1,2 \mathrm{~cm}$. Nerviación rectipalmada. En uno de los nervios de primer orden se constata la presencia de un gran número de nervios de rango inferior (unos 9 pares), con ángulo de divergencia de unos $45^{\circ}$. No podemos llegar a saber si estos eran secundarios o intersecundarios debido a su mal estado de conservación. No se observa nerviación terciaria.

No se puede llegar a determinar este resto foliar a nivel específico. Su morfología podría relacionarse con la de Acer decipiens Al. Br., del Mioceno de Europa occidental. Sin embargo, esta especie se presentaba claramente trilobulada (Walther, 1972), siendo con seguridad pentalobulado el ejemplar estudiado. Además, la especie anteriormente citada presentaba el margen liso, cosa no demostrable en el espécimen al no presentar los márgenes conservados.

\section{ORDEN GENTIANALES A.L. de Jussieu, 1789 Familia Asclepiadaceae R. Brown, 1810 Género Acerates Ellis, 1817}

\section{Acerates cf. veterana Heer, 1855-1859 Fig. 4, D; Lám. II, fig. 6}

Hojas lanceoladas y oblongas; longitud del limbo: 2,38$6,85 \mathrm{~cm}$; anchura: 0,4-0,6 cm; ápice agudo; base cuneada; margen liso; nerviación curvipinnada lazada simple; nervio primario moderado con curso recto; 6-10 pares de nervios secundarios abruptamente curvados, con ángulo de divergencia de unos $45^{\circ}$, siendo casi recto en la zona apical de algunos ejemplares (FM-060); presencia de nervios intersecundarios; nerviación terciaria mal conservada, en algunos ejemplares parece que se encuentra reticulada (FM207).

Se han analizado 46 ejemplares relacionables con la especie del Sarmatiense de Suiza, A. veterana (Heer, 1855-1859). Este autor comparó los ejemplares por él descritos con la especie estadounidense actual $A$. longifolia Michx. No obstante, la morfología de $A$. veterana recuerda la de otras especies fósiles muy alejadas taxonómicamente de ésta, como Myrica arenesi Arènes y Depape, del Oligoceno y Mioceno Inferior de la Península Ibérica e islas Baleares (Sanz de Siria, 1992), y algunos ejemplares de Quercus elaena, especie extendida por el Oligoceno y Mioceno de toda Europa.
Debido a la confusión que genera este tipo de morfología foliar, pensamos que es necesaria una revisión de ésta, por lo que asignamos con duda los ejemplares estudiados a la especie Acerates veterana.

ORDEN LILIALES Lindley, 1833

Familia Liliaceae A.L. de Jussieu, 1789

Género Smilax Linné, 1753

\section{Smilax sp.}

Fig. 5, K; Lám. I, fig. 4

Fragmentos foliares en los que faltan los márgenes, ápices y bases. El ejemplar más completo es el FM-230, que presenta una forma ovada; longitud conservada: $2,7 \mathrm{~cm}$; anchura: 2,9 cm. Por su parte, el ejemplar JLBV-222 tiene una longitud de $3,44 \mathrm{~cm}$ y una anchura de $2,34 \mathrm{~cm}$. La nerviación de ambos ejemplares es arqueado-estriada, observándose tres nervios primarios que debieron nacer en la base de las hojas. Se desarrolla en el centro de los limbos un conjunto de nervios de segundo orden que unen los nervios primarios, naciendo de estos con ángulos de divergencia de agudos a rectos. En el ejemplar FM-230 se observa que la nerviación secundaria que parte de los nervios primarios laterales se desarrolla de forma paralela y surge de los nervios primarios con ángulo recto. No se observa nerviación terciaria ni ninguna de menor rango.

Se han estudiado dos únicos ejemplares relacionables sin duda con el género Smilax. Su estado de conservación no es el óptimo, por lo que no podemos asignarlos a ninguna especie concreta de este género, de muy amplia distribución estratigráfica durante el Terciario.

Incertae sedis

Género Lomatites Saporta, 1862

\section{Lomatites sp.}

Fig. 4, J; Lám. II, fig. 2

Restos foliares elípticos, de pequeño tamaño; longitud del limbo: 2,5-4,4 cm; anchura: 0,65-0,8 cm; ápices no conservados, posiblemente agudos; bases cuneadas; margen, por lo general, liso, aunque en algunos ejemplares (CJLBV016, CJLBV-187) pudo haber sido ligeramente aserrado; nerviación curvipinnada multiarqueada; nervio medio de moderado a robusto con curso recto; 5-7 pares de nervios secundarios de grosor moderado, curvados abruptamente con ángulo apical menor de $45^{\circ}$; presencia de nervios intersecundarios y arcos inframarginales; nerviación terciaria percurrente, de curso fundamentalmente recto y disposición oblicua con respecto al nervio medio; no se observa nerviación de rango inferior.

El estudio de 4 ejemplares revela una morfología semejante a la de las especies suizas sarmatienses Pimelea pulchella Heer y Carya integriuscula Heer. Sin embargo, en el primer caso la especie mencionada posee unas hojas claramente oblanceoladas, mientras que en el segundo, su tamaño es mucho mayor apreciándose una zona basal lisa y un ápice dentado (Heer, 1855-1859). 
Los especímenes estudiados son comparables con los que Saporta (1873) incluyó en el género parataxónico Lomatites, y describió como L. salicinus y L. aquenses en el Oligoceno de Aix en Provence. Debido a que posiblemente estas dos especies sean polimorfismos de una sola y dado el escaso número de ejemplares estudiados por nosotros, los atribuimos al género Lomatites sin relacionarlos con ninguna especie en particular.

\section{ASPECTOS TAFONÓMICOS}

Se han estudiado 1.096 ejemplares de los cuales algo más de la mitad eran indeterminables (Fig. 3). Entre estos hemos de destacar la presencia de fragmentos de pinnas y pinnulas de Filicales (Fig. 5, H); ramas de gimnospermas, tal vez relacionables con la familia Taxodiaceae; restos foliares de angiospermas dicotiledóneas (Fig. 5, D) algunos de los cuales presentan cierto parecido con hojas de los géneros Myrica y Quercus; fragmentos de restos foliares lineares y paralelinervios de monocotiledóneas de la subclase Commelinidade (Fig. 5, M), que dadas sus características morfológicas podrían haber pertenecido a plantas de las familias Poaceae, Cyperaceae, Sparganiaceae y Juncaceae; un fragmento de rizoma (Lám. I, fig. 8) también relacionable por las mismas razones con las familias de la subclase mencionada; y una inflorescencia amentiforme (Lám. II, 10), no muy bien conservada, en la que no se observan estructuras florales definidas, por lo que podría ser atribuida a varios de los géneros identificados, como Populus, Juglans, Quercus y Myrica.

Todos los fósiles que se estudian en este trabajo aparecen sobre o en el interior de concreciones. Este término se refiere a la porción de una roca sedimentaria que ha sido cementada diferencialmente en su medio, resultando de la precipitación de material autigénico (Sellés-Martínez, 1996).

Las concreciones del afloramiento de Izarra, como revela un análisis de su composición mineralógica, están formadas casi exclusivamente por calcita, y presentan un diámetro de $10 \mathrm{~cm}$ por 2-3 de grosor, con formas distintas que van desde cilíndricas a subesféricas. El estudio de estas concreciones mediante láminas delgadas revela una estructura laminada, lo que las asemeja a las halladas en el Cámbrico Superior del Sur de Gales, incluidas por Raiswell (1971) en el grupo de las "parallel laminae".

La formación de concreciones carbonáticas indica la existencia de fondos lacustres con un extenso desarrollo de velos microbianos, en donde la existencia de organismos pastadores y detritívoros, tales como ciertos invertebrados, se encontraba inhibida. Esta inhibición pudo ser debida a la formación de lechos hipersalinos a consecuencia del lavado de los materiales del diapiro de Murguía. Según Martill (1988), estos velos podrían tener también un papel importante al restringir la colonización de los fondos a infauna y epifauna tolerante a la hipersalinidad. Así, Gall (1990) explica que los velos microbianos producen mucílagos y crean un medio cerrado pobre en oxígeno. Allison (1988) sugiere que estos lechos estarían compuestos por cianobacterias.

En una etapa bioestratinómica, los restos vegetales que flotaban en la superficie de las aguas de la zona lacustre de Izarra, y que de forma mayoritaria debieron llegar mediante transporte eólico y acuático, se habrían hundido por saturación y habrían caído al fondo en donde se desarrollaban los velos microbianos. Según Martill (1988) y Gall (1990), estos contribuyen a la captación de los restos, muchas veces colonizándolos en su superficie e impidiendo su desarticulación.

Según Berner (1968), la asociación de concreciones con fósiles ha llevado a la especulación de que la descomposición bacteriana de las partes blandas de un organismo es una causa importante de la precipitación autigénica del $\mathrm{CO}_{3} \mathrm{Ca}$. Aunque, como expone SellésMartínez, (1996), no todas las concreciones se encuentran asociadas a fósiles. En el caso del afloramiento de Izarra, todas ellas poseen microfósiles tales como valvas de ostrácodos y palinomorfos, además de fragmentos de carbon y metano, lo que junto a su estructura laminada parece indicativo de una inequívoca intervención microbiana en su formación.

Posiblemente, una vez retenidos los restos orgánicos en los tapices microbianos comenzaron a sufrir una descomposición aerobia que condujo a una ligera caída en el ph de las aguas a causa de la producción de $\mathrm{CO}_{2}$ y distintos tipos de ácidos como el carbónico.

Existen microorganismos que se alimentan de proteinas y que su acción no sólo produce la liberación de sustancias ácidas, sino también básicas, como amonio y aminas (Berner, 1968). Si el nitrógeno se libera en forma de amonio y de otras bases, es posible que la descomposición inicial de la materia orgánica tenga como resultado un aumento del ph en lugar de un descenso. Esto conlleva a la precipitación de $\mathrm{CO}_{3} \mathrm{Ca}$ autigénico sobre el resto, depositándose de esta manera una primera lámina de $\mathrm{CO}_{3} \mathrm{Ca}$. Este proceso se repite hasta la formación de la concreción. Allison (1988) postula que la producción de sustancias iónicas activas sobre un resto orgánico hace que se formen precipitados de minerales propios de una diagénesis temprana sobre estos y así se detenga totalmente su degradación.

En el caso particular de las concreciones de la Formación Santana de Brasil, las responsables de la liberación de amonio al medio y del depósito de carbonatos fueron bacterias anaerobias sulfato reductoras (Martill, 1988). En el caso que nos ocupa, no podemos afirmar que sean este tipo de microorganismos los responsables de la formación de las concrecciones, ya que los estudios de las láminas delgadas realizados no son resolutivos, pero su efecto fue el mismo.

Las concreciones estudiadas poseen un tamaño pequeño, por lo que los restos vegetales de gran talla no quedaron conservados en sus materiales o lo hicieron de forma muy parcial.

El conjunto de los taxones determinados tras el estudio taxonómico se puede dividir en tres categorías a la vez paleobiológicas y tafonómicas:

1- Taxones démicos representados por elementos autóctonos, que corresponderían a plantas hidrófitas 
que vivían en el medio acuático o en sus proximidades, entre las que se encontrarían: Salvinia sp., Nymphaeaceae y especies de Commelinidae.

2- Taxones démicos representados por elementos alóctonos, representados por las plantas ripícolas, entre las que se pueden destacar: Daphnogene polymorpha y Byttneriophyllum tiliaefolium, entre otras.

3- Taxones adémicos representados por elementos alóctonos, tratándose de plantas que habitaron en las zonas emergidas de la cuenca que no necesitaron de una humedad edáfica permanente para su desarrollo, como Pinus sp., Tetraclinis salicornioides y Caesalpiniaceae.

\section{ASPECTOS PALEOECOLÓGICOS}

Del conjunto de los taxones reconocidos, la mayoría corresponde, según la clasificación de Gregor (1982), a restos foliares cinnamomoides y lauroides de angiospermas dicotiledóneas. Se destaca por su abundancia la especie Daphnogene polymorpha que es la más abundantemente recogida en el afloramiento, con un porcentaje de 15,51\% sobre el total (Fig. 3). En segundo lugar, destaca la abundancia de Byttneriophyllum tiliaefolium, con un tanto por ciento de $5,11 \%$ (Fig. 3). Los valores que presentan estas dos especies son posiblemente debidos a que formaron parte de los ecosistemas ripícolas de la zona.

Las comunidades vegetales que existieron en la región debieron sustentarse durante una buena parte del año gracias a la humedad edáfica, encontrándose compuestas por una gran candidad de elementos propios de la Geoflora Paleotropical, como: Daphnogene, Laurophyllum, Myrica, Byttneriophyllum, Sterculiaceae, Caesalpiniaceae, Sapindus, Celastrophyllum, Berchemia, Acerates y Lomatites. Mai (1989) califica a estas comunidades como "formaciones de bosque de laureles y coníferas mediatizadas edáficamente". Los elementos arctoterciarios se han encontrado en mucha menor proporción, destacándose: Osmunda, Pinus, Tetraclinis, Juglans?, Quercus, Populus, Acer y Smilax.

Para ubicar estas comunidades en una hipotética cadena de vegetación, creemos apropiado adoptar la nomenclatura de Havlena (1970) y Pfefferkorn (1980). Así, en las llamadas "lowlands", tierras bajas con pequeñas diferencias de elevación y laderas con una inclinación moderada, debieron desarrollarse las comunidades hidrófitas, constituidas por taxones démicos representados por elementos autóctonos, y ripícolas, formadas por taxones démicos representados por elementos alóctonos. Por su parte, en las zonas que rodeaban la cuenca y que no tenían influencia de los sistemas lacustres, se desarrollaron comunidades de tipo "extrabasinal", con taxones adémicos representados por elementos alóctonos.

En las comunidades arbóreas y arbustivas ripícolas es en donde se debieron desarrollar la mayor parte de las angiospermas determinadas, y su taxón dominante pudo ser Daphnogene polymorpha.
El género Daphnogene fue un componente importante de la vegetación de algunos ecosistemas terciarios del centro de Europa, desarrollándose sus diferentes especies tanto en zonas no influenciadas por las aguas (Hably, 1988, 1990), como en bosques riparios (Kvaček y Hably, 1991). Nosotros pensamos que posiblemente $D$. polymorpha fue el constituyente más importante de los bosques ribereños de la zona de estudio debido a su abundancia que, como ya se ha indicado, es la más alta del conjunto de los taxones determinados.

Además del género Daphnogene, estas comunidades estarían integradas por: Myrica longifolia, Laurophyllum sp., Populus balsamoides, Byttneriophyllum tiliaefolium, Juglans? acuminata, Diospyros? brachysepala, Sapindus sp. y Commelinidae. En zonas con una humedad edáfica menor, quizás también ligadas a estas comunidades, debieron desarrollarse Acer sp., Quercus cf. buchii y Berchemia multinervis. Es posible que Tetraclinis salicornioides también se integrara en esta comunidad, aunque no podemos afirmarlo taxativamente. Según Hably (1979), los requerimientos ecológicos de esta especie todavía no están claros.

Los bosques ripícolas de la región debieron estar constituidos por una mezcla de taxones notófilos perennifolios y mesófilos caducifolios.

Algunos autores, como Sanz de Siria (1992), trataron de relacionar asociaciones registradas cenozoicas en donde dominan numéricamente restos foliares asignables a la familia Lauraceae, con comunidades vegetales que existen actualmente en regiones tropicales y subtropicales. En la actualidad, las lauráceas suelen formar cinturones de vegetación perennifolia en zonas montañosas caracterizadas por la existencia de nieblas. Si analizamos el conjunto de la flora estudiada, posiblemente éste no fue el caso de la cuenca de Izarra, ya que las laurisilvas se desarrollaron gracias a la humedad edáfica producida por el sistema lacustre. Luego, no parece posible aplicar el actualismo en este caso y, seguramente, las lauráceas fueron abundantes en las comunidades ripícolas del Terciario de Izarra. En éstas se integraron otros árboles de distintas familias que con seguridad presentaron un carácter caducifolio y perdían sus hojas en las estaciones más calurosas. Este debió ser el caso de Quercus, Acer, Populus y Byttneriophyllum. En estas comunidades crecieron plantas lianoides, como Smilax sp. y, posiblemente, Byttneriophyllum tiliaefolium, cuya entrada en el medio acuático se vería facilitada al desarrollarse sobre árboles y arbustos; y su sotobosque se encontraría principalmente poblado por helechos.

Las comunidades de tipo "extrabasinal" probablemente también tuvieron elementos de tipo caducifolio, como Sterculiaceae. El aspecto de éstas debió ser el de un matorral, o un bosque de coníferas bastante abierto en donde habitarían: Tetraclinis salicornioides, Pinus sp., Sterculiaceae, Caesalpiniaceae, Acerates cf. veterana y Lomatites sp. Las plantas que integraron esta comunidad estarían adaptadas a soportar estaciones secas.

Como se puede observar en la Figura 3, el número de angiospermas recolectadas supera con creces el de gimnospermas. Esto se debe a dos razones fundamentales: 
a) Dominancia de las angiospermas en las comunidades de los "lowlands".

b) Las condiciones de transporte por viento y agua en el caso de Izarra favorecieron el depósito de angiospermas en detrimento de las gimnospermas. Con respecto a esto, algunos autores como Wagner (1997) indican que la biodegradación parece ser el factor más importante en la desarticulación de los restos vegetales y que su destrucción mecánica es secundaria. No obstante, la gran representación de dicotiledóneas arbóreas entre los macrorrestos indica condiciones de baja energía de las aguas, ya que si hubiera habido una alta energía hidráulica los restos foliares de las angiospermas, a causa de su morfología y anatomía, hubieran sido destruidos (Spicer y Wolfe, 1987). Dada esta baja energía, se pudieron desarrollar plantas como Salvinia y Nymphaeaceae.

La mayor parte de los taxones determinados son mesotérmicos y mega-mesotérmicos (Fig. 3), lo que parece señalar que el clima de la zona debió ser de tipo subtropical, presentando un período cálido y seco, ratificado por la presencia de Sterculiaceae y Caesalpiniaceae, posiblemente durante el cual algunas plantas, principalmente mesófilas, perdían su foliación. Esto parece coincidir con lo inferido del estudio de las floras del Mioceno Inferior y Medio de Cataluña (Sanz de Siria, 1994), y las del Eggeburgiense de Znojmo (Moravia) (Knobloch, 1992). Por otra parte, el estudio fisonómico de la macroflora arroja una predominancia de taxones notófilos de margen liso frente a mesófilos con margen aserrado (Fig. 3), lo que parece confirmar la subtropicalidad del clima.

Por todo lo expuesto, la vegetación templada inferida por Fernández Marrón (1996), a partir de datos palinológicos, no se encuentra de acuerdo con los datos climáticos deducidos a partir de macrorrestos. Posiblemente esto sea debido a problemas de tipo tafonómico por transporte de pólenes desde zonas alejadas de la cuenca.

\section{EDAD DE LA FLORA}

El estudio preliminar sobre la macroflora de Izarra es de índole bioestratigráfica (Fernández Marrón et al., 1979). Estos autores propusieron una edad Estampiense para el afloramiento debido a la presencia de las especies: Laurus protodaphne Sap., Drepanocarpus punctulatus Sap. y Pistacia reddita Sap., que fueron determinadas a partir de ejemplares incompletos y muy deteriorados (Fernández Marrón et al., op. cit., lám. 1, figs. 2 y 10). Por otra parte, únicamente hemos podido confirmar la presencia de dos de los 37 taxones mencionados por los autores anteriores: Byttneriophyllum tiliaefolium, típicamente mioceno, y Acer sp.; y la figuración que posee este trabajo no ayuda a aclarar la presencia de los 35 restantes. Por estas razones, pensamos que la colección de los autores citados debiera ser reestudiada, reconsiderándose la datación estratigráfica propuesta.

Recientemente, Fernández Marrón (1996) a partir de datos proporcionados por palinomorfos, que compara con los estudiados en las cuencas tributarias del valle del Ródano por Sittler (1984), dató de nuevo el afloramiento como correspondiente al Chatiense (zona polínica SP 8a de Sittler). La autora argumentó esta datación al apreciar un desarrollo explosivo de coníferas en el seno de una rica flora mediterránea de clima templado. Sin embargo, altos porcentajes de gimnospermas y presencia de taxones de tipo mediterráneo se observan en el $\mathrm{O}$ de Europa desde el Eoceno hasta la actualidad (Bessedik, 1984, 1985; Cavagnetto y Anadón, 1996).

La edad miocena de Izarra viene dada por la presencia de una serie de especies exclusivas de este período, como: Osmunda parschlugiana, Daphnogene polymorpha, Byttneriophyllum tiliaefolium y Berchemia multinervis. Si bien hemos de destacar la presencia de Tetraclinis salicornioides, Myrica banksiaefolia, Juglans? acuminata, Populus balsamoides y Acerates cf. veterana, cuyos rangos estratigráficos comienzan en el Oligoceno.

Más concretamente, la macroflora estudiada presenta la mayor parte de los taxones en común con la del Sarmatiense (Mioceno Medio) de Oehningen, Suiza (Heer, 1855-1859; Hantke, 1954, 1965), salvo Lomatites sp. y Sterculiaceae gen. et sp. indet, a diferencia de lo observado por Fernández Marrón et al. (1979), quienes la compararon con la del Paleógeno de Francia (Saporta, 1865, 1867, 1873; Laurent, 1899) y la Cuenca del Ebro (Sanz de Siria, 1992). La asociación paleoflorística estudiada presenta una mayoría de elementos de tipo paleotropical, siendo más escasos los arctoterciarios, lo que es coincidente con el conjunto de datos paleobotánicos que se conocen en la Península Ibérica para el Mioceno Inferio y Medio, así como para el Superior más basal.

Así pues, con base en los datos macroflorísticos, el afloramiento de Izarra debiera asignarse al Mioceno. Sin embargo, aunque la macroflora de Izarra se asemeja a la de Oehningen, la atribuimos con duda al Mioceno Medio, ya que hemos encontrado especies exclusivamente miocenas, como Osmunda parschlugiana y Byttneriophyllum tiliaefolium, con rangos estratigráficos que también abarcan el Mioceno Superior (Hably,1992). Además, para una correcta datación se necesitarían datos paleontológicos complementarios proporcionados por otros grupos fósiles.

Por estas razones, consideramos que la datación del afloramiento de Izarra era errónea; no corresponde a ningún piso del Oligoceno. Los datos paleoflorísticos aportados por nosotros indican una edad neógena, ya apuntada a partir de consideraciones geológicas (Stackelberg, 1960; Ramírez del Pozo y Del Olmo Zamora, 1979), correspondiente con duda al Mioceno Medio.

\section{CONCLUSIONES}

Izarra es un afloramiento terciario ubicado en el $\mathrm{N}$ de la Península Ibérica, que presenta sus fósiles reunidos en 
o sobre concreciones calcáreas formadas por la acción de microorganismos en fondos lacustres hipersalinos.

Tras el estudio macroflorístico, se han determinado 31 taxones, la mayoría de los cuales corresponden a angiospermas dicotiledóneas debido a las condiciones de baja energía del sistema lacustre. Se han identificado taxones démicos representados por elementos autóctonos, taxones démicos representados por elementos alóctonos y taxones adémicos representados por elementos alóctonos, los cuales seguramente se integraron respectivamente en comunidades acuáticas, ripícolas y terrícolas no influenciadas por las aguas del lago.

En la distribución de las comunidades vegetales se distinguen dos grupos: las que se desarrollaban en los "lowlands" y las de tipo "extrabasinal", las cuales se caracterizaron por la diferente humedad edáfica que soportaron. En los "lowlands" se desarrollaron comunidades acuáticas y ripícolas, estas últimas presentarían el aspecto de una laurisilva salpicada con árboles de hojas mesófilas. Por su parte, el aspecto de las comunidades de tipo "extrabasinal" debió ser un bosque abierto de coníferas.

Las especies mejor representadas son propias de ecosistemas ribereños, destacándose Daphnogene polymorpha y Byttneriophyllum tiliaefolium por el número de ejemplares estudiados. En zonas no influenciadas por las aguas se infiere el desarrollo de un matorral, en el que participaron distintas especies de Caesalpiniaceae y Acerates cf. veterana, posiblemente integrado en un bosque abierto de Pinus y Tetraclinis salicornioides.

La mayoría de los taxones determinados son mesotérmicos y mega/mesotérmicos, y el estudio fisonómico de los macrorrestos señala una mayor proporción de taxones notófilos de margen liso. Estos datos parecen indicar que en la zona se desarrolló un clima de carácter subtropical, posiblemente con una estación seca acentuada, como indica la presencia de representantes de las familias Sterculiaceae y Caesalpiniaceae. La presencia de elementos mesófilos podría indicar un período de abscisión foliar que pudo corresponder con la estación más seca.

La presencia de especies exclusivas del Mioceno, como Osmunda parschlugiana, Daphnogene poly-morpha, Byttneriophyllum tiliaefolium y Berchemia multinervis nos permite atribuir a este período los materiales del afloramiento, anteriomente considerados oligocenos. La macroflora estudiada presenta una elevada cantidad de taxones comunes con la del Sarmatiense de Oehningen (Suiza). Sin embargo, para realizar una datación más precisa se necesita la ayuda de otros grupos fósiles.

\section{AGRADECIMIENTOS}

Este trabajo no hubiera podido realizarse sin la inestimable colaboración de Jesús Alonso, director del Museo de Ciencias Naturales de Álava, y Carmelo Corral y Rafael López del Valle, de la misma Institución. También me gustaría reconocer la ayuda prestada por el Dr. Santiago
Falces en la preparación de las láminas delgadas de las concreciones. Por su auxilio en la parte gráfica debo mencionar a Maria da Graça Nogueira Marques, de la Universidade de Aveiro, Eulogio Martín, de la Universidad Complutense de Madrid y a Rafael Cano. Asímismo, quiero expresar mi agradecimiento a los señores José Luis Bueso, Javier Sáenz, Joseba Fernández de Pinedo, Félix Murguía y José María Moreno, y a Doña Carmela Aranguren, por dejarme acceder a sus colecciones.

Por último, me gustaría destacar las importantes apreciaciones de índole científica que realizaron a este trabajo la Dra. Carmen Diéguez Jiménez y el Dr. Robert H. Wagner.

Este trabajo ha sido financiado por el Museo de Ciencias Naturales de Álava gracias a un proyecto desarrollado durante el año 1995, y a una beca de investigación de la Diputación de Álava, tutorizada por el citado Museo, que disfruté durante el año 1996.

\section{BIBLIOGRAFÍA}

Álvarez Ramis, C. y Fernández Marrón, M.T. 1975. Estudio paleobotánico y datación estratigráfica del yacimiento terciario de Frías (Burgos). Primer Centenario de la Real Sociedad Española de Historia Natural. Sección Geológica, 1, 27-41.

Allison, P.A. 1988. Konservat-Lagerstätten: cause and classification. Paleobiology, 14, 331-344.

Andreánszky, G. 1959. Die Flora der Sarmatischen stufe in Ungarn (Die paläoökologische und zönologischen Beziehungen ihrer Entwicklungsgeschichte). Geologische (bersicht von Zoltán Schréter, Budapest, 1-360.

Andreánszky, G. 1966. On the upper Oligocene flora of Hungary. Analysis of the site at the Wind Brickyard, Eger. Studia Biologica Hungarica, 5, 1-151.

Arènes, J. et Depape, G. 1956. La flore burdigalienne des iles Baléares (Majorque). Revue Générale de Botanique, 63, 347-390.

Arillo, A. 1994. Nota sobre una larva de Odonato del Oligoceno de Izarra (Alava) en la colección del Museo Geominero (Odonata, Anisoptera, Libellulidae). Boletín Geológico y Minero, 105, 325-328.

Arillo, A. \& Ortuño, V.M. 1997a. First records of the families Anthicidae and Chrysomelidae from the Oligocene of Izarra (Álava, Spain). Coleopterist's Bulletin, 51(3), 293-297.

Arillo, A. \& Ortuño,V.M. 1997b. The fossil Acrididae from the Oligocene of Izarra (Alava, Spain). The antiquity of gregarious behavior. (Orthoptera, Caelifera). Geobios, 30, 231-234.

Arillo, A., Nel, A. \& Ortuño, V.M. 1996. Two fossil bees from the Oligocene of Izarra (Álava, North of Spain) (Hymenoptera, Apoidea). Bulletin de la Societé Entomologique de France, 101, 59-64.

Bailey, I.W. \& Sinnot, E.W. 1915. A botanical index of Cretaceous and Tertiary climates. Science, 41, 831-834.

Bailey, I.W. \& Sinnot, E.W. 1916. The climatic distribution of certains types of angiosperm leaves. American Journal of Botany, 3, 24-39. 
Barrón, E. 1993. Taphonomic studies of the plant remains from the Ceretana Basin (Lérida, Spain). Kaupia, 2 , 127132.

Barrón, E. 1996. El paragénero Daphnogene Unger (Lauraceae) en el Oligoceno de Izarra (Álava). Estudios del Museo de Ciencias Naturales de Alava, 10-11, 45-52.

Barrón, E., Rivas Carballo, M. R. y Valle, M. F. 1996. Síntesis bibliográfica de la vegetación y clima de la Península Ibérica durante el Neógeno. Revista Española de Paleontología, $\mathbf{n}^{\mathbf{0}}$ Extraordinario, 225-236.

Barrón, E., Ortuño, V. y Arillo, A. 1997. Estudio paleontológico del afloramiento mioceno de Izarra (Álava, España). Estudios del Museo de Ciencias Naturales de Álava, 12, 5-15.

Becker, H.F. 1972. The Metzel Ranch flora of the Upper Ruby River Basin, Southwestern Montana. Palaeontographica. Abteilung B, 141(1-2), 1-61.

Becker, H.F. 1973. The York Ranch flora of the Upper Ruby River Basin, Southwestern Montana, Palaeontographica. Abteilung B, 143(1-4), 18-93.

Berner, R. A. 1968. Calcium carbonate concretions formed by the decomposition of organic matter. Science, $\mathbf{1 5 9}$, 195-197.

Bessedik, M. 1984. The early Aquitanian and upper Langhian-lower Serravallian environments in the northwestern mediterranean region. Paleobiologie Continentale, 14(2), 153-179.

Bessedik, M. 1985. Reconstitution des environnements miocènes des régions nord-ouest méditerranéennes à partir de la Palynologie. Thèse d'État. Académie de Montpellier. Université des Sciences et Techniques du Languedoc, Montpellier, 1-162.

Braun, A. 1836. In: Geology and Mineralogy considered with reference to Natural Theology (Ed. W. Buckland). London, I, 510-514.

Braun, A. 1845. Die Tertiär-Flora von Oeningen. Neues Jahrbuch für Mineralogie, Geognosie, Geologie und Petrefaktenkunde, Stuttgart, 1, 164-174.

Brinkmann, R. \& Lögters, H. 1968. Diapirs in Western Pyrenees and Foreland, Spain. In: Diapirism and diapirs (Eds. J. Braustein \& G.D. O'Brien). The American Association of Petroleum Geologists, Tulsa, Oklahoma, U.S.A., 275-292.

Buzek, C., Holy, F. \& Kvaček, Z. 1996. Early Miocene flora of the Cypris Shale (Western Bohemia). Acta Musei Nationalis Pragae, serie B, Historia Naturalis, 52(1-4), 1-72.

Cavagnetto, C. \& Anadón, P. 1996. Preliminary palynological data on floristic and climatic changes during the Middle Eocene-Early Oligocene of the eastern Ebro Basin, northeast Spain. Review of Palaeobotany and Palynology, 92, 281-305.

Ettingshausen, C. 1851. Die tertiären Flora der Umgebung von Wien. Wien, 1-36.

Ferguson, D.K. 1974. On the taxonomy of recent and fossil species of Laurus (Lauraceae). Botanical Journal of the Linnean Society, 68, 51-72.

Fernández López, S. 1981. La evolución tafonómica (un planteamiento neodarwinista). Boletín de la Real Sociedad Española de Historia Natural (Sección Geológica), 79, 243-254.
Fernández López, S. 1991. Taphonomic concepts for a theoretical biochronology. Revista Española de Paleontología, 6, 37-49.

Fernández Marrón, M.T. 1996. Asociación esporopolínica del Oligoceno de Izarra (Álava). Revista Española de Micropaleontología, 28(3), 93-100.

Fernández Marrón, M.T., Olivé, A., Del Olmo, P. y Portero, J.M. 1979. La flora terciaria del yacimiento de Izarra (Álava) y sus implicaciones cronoestratigráficas. Boletín Geológico y Minero, 90(1), 6-12.

Ferrer, J., Fernández Marrón, M.T. y Liñán, E. 1993. Nota sobre las plantas fósiles del Mioceno de Épila (Zaragoza). Geogaceta, 14, 94-97.

Friis, E.M. 1977. Leaf whorls of Cupressaceae from the Miocene Fasterholt flora, Denmark. Bulletin of the Geological Society of Denmark, 26, 103-113.

Gall, J.-P. 1990. Les voiles microbiens. Leur contribution à la fossilisation des organismes au corps mou. Lethaia, 23, 21-28.

Gaudin, C. T. et Strozzi, C. 1864. Contribution à la flore italienne. Sixième mémoire. Neue Denkschrifte allgemeine Geschichtforschende Gesellschaft Naturwissenschaftliche, 22, 1-31.

Givulescu, R. 1996. Quelques observations concernant l'anisophyllie des feuilles du genre Daphnogene Unger 1845 (Lauraccae). Studii Si Cercetari (St. Naturii), 2, 4351.

Givulescu, R. und Olos, E. 1973. Paläobotanische Studien im Tertiär Siebenbürgens. Institul Geologic Bucaresti, Memorii, 19, 1-60.

Givulescu, R., Petrescu, I. et Barbu, O. 1996. Observations concernant les feuilles de Daphnogene Unger, 1845 (Lauraceae, Magnoliophyta) de l'Oligocene de Cornesti/Aghires (Département de Cluj, Roumanie). Tertiary Research, 17(1-2), 1-4.

Goeppert, H. 1855. Die tertiäre Flora von Schossnitz in Schlesien. Heyn'sche Buchhandlung. Görlitz, 1-52.

Gregor, H.J. 1982. Eine Methode der ökologischstratigraphischen Darstellung und Einordnung von Blattfloren unter spezieller Berucksichtigung der TertiärAblagerungen Bayerns. Verhandlungen der Geologischen Bundesanstalt-A, 2, 5-19.

Hably, L. 1979. Some data to the oligocene flora of the Kiscellian Tard Clay, Hungary. Annales HistoricoNaturales Musei Nationales Hungarici, 71, 33-53.

Hably, L. 1985. Early Miocene plant fossils from Ipolytarnóc, N. Hungary. Geologica Hungarica, serie Paleontologica, 44-46, 133-255.

Hably, L. 1988. Egerian fossil flora from Kesztölc, NW Hungary. Studia Botanica Hungarica, 20, 33-61.

Hably, L. 1989. The Oligocene flora of Nagysáp. Fragmenta Mineralogica et Palaeontologica, Budapest, 14, 83-99.

Hably, L. 1990. Egerian plant fossil from Vértesszolos, NW Hungary. Studia Geologica Hungarica, 22, 3-78.

Hably, L. 1992. Early and late Miocene Floras from the Iharosberény-I and Tiszapalkonya-I Boreholes. Fragmenta Mineralogica et Palaeontologica, Budapest, 15, 7-40.

Hably, L. 1993. Egerian macroflora from the Andornaktálya sandpit (Hungary). Studia Botanica Hungarica, 24, 5-22. 
Hably, L. 1994. Egerian plant fossils from Pomáz, Hungary. Fragmenta Mineralogica et Palaeontologica, Budapest, 17, 5-70.

Hably, L. \& Kvaček, Z. 1997. Early Pliocene plant megafossils from the volcanic area in West Hungary. In: Early Pliocene volcanic environment, flora and fauna from Transdanubia, West Hungary (Ed. L. Hably). Hungarian Natural History Museum, Budapest, 5-151.

Hantke, R. 1954. Die fossile Flora der obermiozän Oehningen-Fundstelle Schrotzburg (Schienenberg, SüdBaden). Denkschriften der Schweizerischen Naturforschenden Gesellschaft, Zürich, 80(2), 1-118.

Hantke, R. 1965. Die fossilen Eiden und Ahorne aus den Molasse der Schweiz und von Oehningen (Süd-Baden). Eine Revision der von Oswald Heer diesem Gattungen zugeordneten Resten. Neujahrsblatt der Naturforschenden Gesellschaft, Zürich, 167, 1-140.

Havlena, V. 1970. Einige Bemerkungen zur Phytogeographie und Geobotanik des Karbons und Perms. Sixième Congrès International de Stratigaphie et de Géologie du Carbonifère, Sheffield 1967, Compte Rendu, 3, 901-911.

Heer, O. 1855-1859. Flora Tertiaria Helveticae. Die Tertiäre flora der Schweiz. Winterthur, I, 1-117, II, 1110, III, 1-378.

Hickey, L.J. 1973. Classification of the architecture of dycotiledonous leaves. American Journal of Botany, 60(1), 17-33

Knobloch, E. 1969. Tertiäre Floren von Mähren. Brno, 1201.

Knobloch, E. 1992. Comparisons between the Cretaceous and Tertiary floras of Central and Southwest Europe: a commentary. Revista Española de Paleontología, 7, 161165.

Knobloch, E. und Kvaček, Z. 1965a. Byttneriophyllum tiliaefolium (Al. Braun) Knobloch and Kvaček in der tertiären Floren der Nordhalbkugel. Sbornik Geologickych Vestník Reihe Praha, 5, 123-166.

Knobloch, E. und Kvaček, Z. 1965b. Einige neue Erkenntnisse (ber "Ficus" tiliaefolia (Al. Braun) Heer. Neues Jahrbuch für Geologie und Paläontologie. Abhandlungen, 121, 201-208.

Kvaček, Z. 1989. Fosilní Tetraclinis Mast. (Cupressaceae). Casopis Národniho Muzau v Praze, 155(1-2), 45-54.

Kvaček, Z. \& Hably, L. 1991. Notes on the Egerian stratotype flora at Eger (Wind brickyard), Hungary, Upper Oligocene. Annales Historico-Naturales Musei Nationalis Hungarici, 83, 49-82.

Kvaček, Z. und Walther, H. 1974. Bemerkenswerte und seltene cinnamomoide Blätter aus dem Gremzbereich des Oligo-Miozäns Mitteleuropas. Abhandlungen des Staatlichen Museums für Mineralogie und Geologie zu Dresden, 21, 197-221.

Laurent, L. 1899. Flore des calcaires de Celas. Thèses présentés à la Faculté des Sciences de Marseille, 4, 1148.

Mai, D.H. 1989. Development and regional differentiation of the European vegetaion during the Tertiary. Plant Systematics and Evolution, 162, 79-91.

Mai, D.H. und Walther, H. 1978. Die Floren der Haselbacher Serie im Weisselster-Becken (Berzirk
Leipzig, DDR). Abhandlungen des Staatlichen Museums für Mineralogie und Geologie zu Dresden, 28, 1-200.

Manchester, S.R. 1987. The fossil history of the Juglandaceae. Monographs in Systematic Botany from the Missouri Botanical Garden, 21, 1-137.

Martill, D. 1988. Preservation of fish in the Cretaceous Santana Formation of Brazil. Palaeontology, 31, 1-18.

Nel, A. et Arillo, A. 1995. Révision de Mastotermes haidingeri (Heer, 1849). Description de deux nouveaux Mastotermes de l'Oligocène de France et d'Espagne (Isoptera, Mastotermitidae). Bulletin de la Societé Entomologique de France, 100, 67-74.

Nel, A., Arillo, A. et Ortuño, V.M. 1995. Découverte du premier Libellulidae Trameinae de l'Oligocène d'Espagne (Odonata, Anisoptera). Bulletin de la Societé Entomologique de France, 100, 487-488.

Nel, A., Arillo, A. \& Ortuño, V.M. 1997. New western palearctic Cenozoic Odonata (Zygoptera and Anisoptera). Bulletin de la Societé Entomologique de France, 102, 265-270.

Ortuño, V.M. \& Arillo, A. 1997. Discovery of the genus Ernobius Thomson, 1859 (Coleoptera, Anobiidae) from the Oligocene of Izarra (Álava, Spain). Coleopterist's Bulletin, 51(1), 71-73.

Pais, J. 1979. La végétation de la basse vallee du Tage (Portugal) au Miocène. Annales Geologiques des Pays Helleniques, tome hors de serie, 2, 933-942.

Pamalarev, E., Usunova, K. \& Bojanova, I. 1991. Fossil plants of class Pinopsida from the Neogene sediments of Satovca graben in Rhodopes region (Southwest Bulgaria). Documenta Naturae, 66, 1-17.

Pfefferkorn, H.W. 1980. A note on the term "upland flora". Review of Palaeobotany and Palynology, 30, 157-158.

Petrescu, I., Givulescu, R. \& Barbu, O. 1995. The Oligocene macro- and microflora from Cornesti-Aghires (NW of Romania)- General view. Review of Paleobiology, 14(1), 209-219.

Pingen, M., Ferguson, D.K. \& Collinson, M.E. 1994. Homalanthus costatus Mai: a new Miocene fruit of Cinnamomum Schaffer (Lauraceae). Palaeontographica. Abteilung B, 232, 155-174.

Ramírez del Pozo, J. y Del Olmo Zamora, P. 1979. Mapa Geológico de España. Escala 1:50.000. Explicación de la hoja 111. Orduña. Instituto Geológico y Minero de España, Madrid, 1-35.

Raiswell, R. 1971. The growth of Cambrian and Liassic concretions. Sedimentology, 17, 147-171.

Raunkiaer, C. 1934. The life forms of plants and statistical plant geography. Clarendon Press, Oxford, 1-632.

Rivas-Carballo, C. 1991. The development of vegetation and climate during the Miocene in the south-eastern sector of the Duero Basin (Spain). Review of Palaeobotany and Palynology, 67, 341-351.

Rivas-Carballo, C., Alonso-Gavilán, G., Valle, M.F. \& Civis, J. 1994. Miocene palynology of the central sector of the Duero basin (Spain) in relation to palaeogeography and palaeoenvironment. Review of Palaeobotany and Palynology, 82, 251-264.

Sanz de Siria, A. 1992. Estudio de la macroflora oligocena de las cercanías de Cervera (Colección Martí Madern del 
Museo de Geología de Barcelona). Treballs del Museu de Geologia de Barcelona, 2, 269-379.

Sanz de Siria, A. 1994. La evolución de las paleofloras en las cuencas cenozoicas catalanas. Acta Geológica Hispánica, 29(2-4), 169-189.

Saporta, G. de. 1863. Études sur la végétation du Sud-Est de la France à 1'époque tertiaire. Annales des Sciences Naturelles (Botanique), (4) 19, 5-124.

Saporta, G. de. 1865. Études sur la végétation du Sud-Est de la France à l'époque tertiaire. Annales des Sciences Naturelles (Botanique), (5) 3, 5-152.

Saporta, G. de. 1867. Études sur la végétation du Sud-Est de la France à l'époque tertiaire. Annales des Sciences Naturelles (Botanique), (5) 8, 5-136.

Saporta, G. de. 1873. Études sur la végétation du Sud-Est de la France à l'époque tertiaire. Révision de la flore des gypses d'Aix. Supplément 1. Annales des Sciences Naturelles(Botanique), (5) 18, 23-146.

Schopf, J. M. 1975. Modes of fossil preservation. Review of Palaeobotany and Palynology, 20, 27-53.

Sellés-Martínez, J. 1996. Concretion morphology, classification and genesis. Earth-Science Reviews, 41, 177-210.

Serrano Oñate, A., Martínez del Olmo, W. y Cámara Rupelo, C. 1989. Diapirismo del Trías salino en el dominio Cántabro-Navarro. In: Libro homenaje a Rafael Soler. Associación de Geólogos y Geofísicos Españoles del Petróleo, A.G.G.E.P., Madrid, 115-121.

Sitár, V. \& Kvaček, Z. 1997. Additions and revisions to the early Miocene flora of Lipovany (Southern Slovakia). Geologica Carpathica, 48(4), 263-280.

Sittler, C. 1984. Essai de zonation palynologique des dépôts paléogènes des tributaires de la vallée du Rhône et du Midi méditerranéen. Géologie de la France, 1-2, 85-90.

Spicer, R. A. \& Wolfe, J. A. 1987. Plant Taphonomy of the Late Holocene deposits in Trinity (Clair Engle) Lake, Northern California. Paleobiology, 13, 227-245.
Stackelberg, U. 1960. Der Diapir von Murguía (Nordspanien). Beiheft zum Geologischen Jahrbuch, 66, 63-94.

Suc, J.P., Clauzon, G., Bessedik, M., Leroy, S., Zheng, Z., Drivaliari, A., Roiron, P., Ambert, P., Martinell, J., Domenech, R., Matías, I., Julià, R. \& Anglada, R. 1992. Neogene and Lower Pleistocene in Southern France and Northeastern Spain, Mediterranean environments and climate. Cahiers de Micropaléontologie, 7, 165-186.

Takhtajan, A. 1991. Evolutionary trends in flowering plants. Columbia University Press, New York, 1-241.

Unger, F. 1840. Über die Pflanzen- und Insekten-Reste von Radoboj in Kroatien. Neues Jahrbuch für Mineraogie und Geologie, 1840, 374-377.

Unger, F. 1847. Chloris protogaea. Beiträge zur Flora der Vorwelt. Leipzig, 1-149.

Unger, F. 1850a. Die fossile Flora von Sotzka. Denkschriften Mathematisch-Naturwissenschaftliche Classe, Akademie der Wissenschaften Wien, 2 130-197.

Unger, F. 1850b. Genera et species plantarum fossilium. Sumptibus Academiae Caesare, Vindobonae, 1-627.

Van Steenis, C. G. G. J. 1962. The land-bridge theory in Botany. Blumea, 11(2), 235-542.

Walther, W. 1972. Studie (ber Terti(re Acer Mitteleuropas. Abhandlungen des Staatlichen Museums für Mineralogie und Geologie zu Dresden, 19, 1-309.

Wagner, R.H. 1997. Floral Paleoecology of the Carboniferous/Permian. In: Registros fósiles e historia de la Tierra (Eds. E. Aguirre, J. Morales y D. Soria). Editorial Complutense, S.A., Madrid, 143-172.

Webb, L.J. 1959. A physiognomic classification of Australian rain forests. Journal of Ecology, 47, 551-570.

Weber, O. 1851. Die Tertiär flora der Niederrheinischen Braunkolenformation. Palaeontographica, Abteilung, 2(4), 115-236.

Zastawniak, E. 1980. Sarmatian leaf flora from the southern margin of the Holy Cross Mts. (South Poland). Prace Muzeum Ziemi, 33, 39-107. 